(2) Open Access Full Text Article

REVIEW

\title{
Interferon-free combination therapies for the treatment of hepatitis C: current insights
}

\author{
This article was published in the following Dove Press journal: \\ Hepatic Medicine: Evidence and Research \\ 2 November 2015 \\ Number of times this article has been viewed
}

\author{
Jacinta A Holmes \\ Alexander J Thompson \\ Department of Gastroenterology, \\ St Vincent's Hospital, University of \\ Melbourne, Fitzroy, Victoria, Australia
}

Correspondence: Jacinta A Holmes Department of Gastroenterology, St Vincent's Hospital, University of Melbourne, Level 4, Daly Wing, 35 Victoria Parade, Fitzroy,

Victoria, Australia

Tel +6I 3 923। 3580

Fax +61392313590

Email Jacinta.holmes@svha.org.au
Abstract: The hepatitis $\mathrm{C}$ virus (HCV) treatment landscape has rapidly changed over the past 5 years. The development of direct-acting antiviral (DAA) agents that specifically target various steps in the HCV lifecycle has revolutionized therapeutic options for patients with HCV, with the development of highly effective and well-tolerated oral interferon-free regimens. There are many DAAs that are currently in development or have recently been approved, which target different nonstructural HCV proteins and host targets that are essential for HCV replication. This review will focus on the different classes of DAAs and the various combinations that are in advanced development for the treatment of chronic HCV infection and will focus on the different regimens in specific patient populations.

Keywords: interferon-free, direct-acting antivirals, HCV therapy

\section{Introduction}

Infection with the hepatitis $\mathrm{C}$ virus (HCV) remains a significant global health issue. ${ }^{1}$ With the aging HCV population, there is a growing burden of complications of chronic HCV infection (CHC), including cirrhosis, decompensated liver disease, and hepatocellular carcinoma. These complications are expected to triple over the next 15 years. ${ }^{2,3}$ However, $\mathrm{CHC}$ is curable, and viral eradication is associated with improved patient survival and reduced complications of CHC. ${ }^{4}$ For the past decade, the only therapy for $\mathrm{HCV}$ has been pegylated-interferon combined with ribavirin (PR). Unfortunately, this therapy is limited by the significant toxicity and suboptimal response rates (overall response rates $54 \%-56 \%$ ). ${ }^{5-7}$ Furthermore, not all patients are eligible for PR therapy. Thus, there has been a desperate need for more efficacious and better-tolerated treatments for $\mathrm{HCV}$.

The development of a cell culture system for HCV and subsequent detailed characterization of the HCV lifecycle have allowed the development of new therapies that directly target steps in the HCV replication cycle, so called direct-acting antivirals (DAAs). ${ }^{8,9}$ The development of these DAAs has rapidly evolved over the past 5 years and has radically changed the HCV treatment paradigm to allow interferon-free regimens, of which several are now approved and available in clinical practice in many countries.

\section{HCV lifecycle}

$\mathrm{HCV}$ is a small enveloped single-stranded RNA virus with a 9,600 nucleotide genome. ${ }^{10}$ HCV gains entry into hepatocytes through a receptor complex. After endocytosis, uncoating occurs and the HCV genomic RNA is released from the nucleocapsid into 
the cytoplasm. Translation into a single large polyprotein occurs in the endoplasmic reticulum, which is cleaved by viral and host proteases into ten mature HCV proteins, including structural proteins ( $\mathrm{HCV}$ core protein and envelope proteins $\mathrm{E} 1$ and E2) and nonstructural proteins (P7, NS2, NS4A, NS4B, NS5A, and NS5B). These viral and host proteins form a membrane-bound replication complex and transcription takes place, which is dependent upon the RNA-dependent RNA polymerase (NS5B polymerase), with the positivestrand RNA serving as the template for transcription. Mature virions are formed, leading to virion budding and release. Each step of the HCV lifecycle could be a potential target for DAAs (Figure 1).

The NS3/4A protease, NS5A protein, and NS5B polymerase are key enzymes in the HCV replication cycle. Posttranslational cleavage of the polyprotein is dependent on the NS3 protease. The NS5B polymerase is required for viral replication. The NS5A protein plays a necessary role in viral replication and assembly. Inhibition of these enzymes are attractive targets for anti-HCV therapy and are currently the most advanced agent in development (Table 1).

\section{Direct-acting antiviral agents}

The ideal DAA has a high barrier to resistance, pangenotypic activity, picomolar potency, few drug-drug interactions (DDIs), minimal toxicity, and a pharmacokinetic profile that allows once daily dosing. The genetic barrier to resistance is the number of amino acid substitutions required to confer resistance to a DAA. DAAs with a low barrier to resistance only require 1-2 substitutions in order to render the drug ineffective, whereas a DAA with a high genetic barrier to resistance requires $\geq 3$ substitutions, and hence drugs with a high barrier to resistance are preferred as the backbone of many interferon (IFN)-free DAA combinations. In addition, the replication fitness of resistance-associated variants (RAVs) needs to be considered, as RAVs with poor replication fitness may not emerge to be dominant under DAA selection pressure (eg, S282T RAV with sofosbuvir [SOF]), whereas

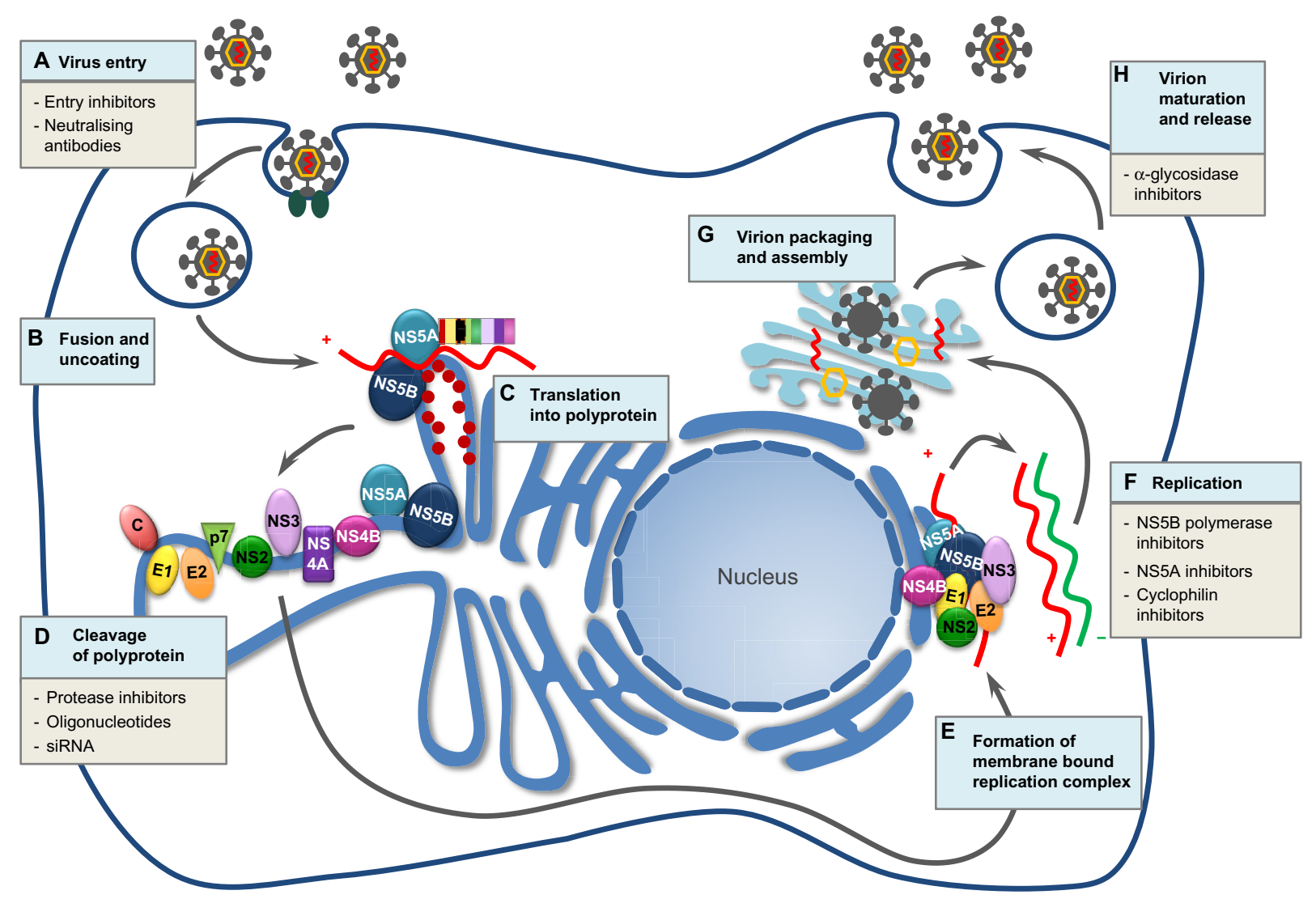

Figure I Hepatitis $\mathrm{C}$ virus (HCV) lifecycle and potential targets for direct-acting antivirals (DAAs).

Notes: (A) The virus gains entry by receptor-mediated endocytosis. (B) Fusion and uncoating occur and the HCV genomic RNA is released from the nucleocapsid into the cytoplasm. (C) Translation into a single large polyprotein occurs in the endoplasmic reticulum. (D) This polyprotein is then cleaved by viral and host proteases into 10 mature $\mathrm{HCV}$ proteins, including structural proteins (HCV core protein and envelope proteins EI and E2) and non-structural proteins (P7, NS4A, NS4B, NS5A, and NS5B). (E) These viral and host proteins form a membrane bound replication-complex. (F) Transcription takes place, dependent upon the RNA helicase (RNA-dependent RNA polymerase or NS5B polymerase) where the positive-strand RNA serves as a template for transcription. (G) Virion assembly occurs in the Golgi apparatus when viral glycoproteins combine with newly produced RNA. (H) Virion maturation, budding and release from the hepatocyte occurs. The site of action of current DAAs are listed at each step in the HCV life cycle. 
Table I Current direct-acting antiviral agents in clinical development

\begin{tabular}{|c|c|c|c|c|c|c|}
\hline \multirow[t]{2}{*}{ Sponsor } & \multirow[t]{2}{*}{ Phase } & \multirow{2}{*}{$\begin{array}{l}\text { NS3/4A protease } \\
\text { inhibitors }\end{array}$} & \multicolumn{2}{|c|}{ NS5B polymerase inhibitors } & \multirow[t]{2}{*}{ NS5A inhibitors } & \multirow{2}{*}{$\begin{array}{l}\text { Host targeting } \\
\text { agents }\end{array}$} \\
\hline & & & nucleos(t)ide & Nonnucleos(t)ide & & \\
\hline \multirow[t]{3}{*}{ AbbVie } & Approved & Paritaprevir (ABT-450) & & Dasabuvir (ABT-333) & Ombitasvir & \\
\hline & & & & ABT-072a & (ABT-267) & \\
\hline & Phase II & ABT-493 & & & ABT -530 & \\
\hline Achillion & Phase II & Sovaprevir (ACH-I625) & $\mathrm{ACH}-3422$ & & $\mathrm{ACH}-3102$ & \\
\hline Boehringer- & Phase III & Faldaprevir (BI 201335) ${ }^{\mathrm{a}}$ & & Deleobuvir (BI 207|27)a & & \\
\hline \multicolumn{7}{|l|}{ Ingelheim } \\
\hline Bristol-Myers & Approved & Asunaprevir & & & Daclatasvir & \\
\hline \multirow[t]{3}{*}{ Squibb } & & (BMS-650032) & & & (BMS-790052) & \\
\hline & Phase III & & & Beclabuvir (BMS-79|325) & & \\
\hline & Phase II & & BMS-986094 & & & \\
\hline \multirow[t]{5}{*}{ Gilead } & Approved & & Sofosbuvir (GS-7997) & & Ledipasvir (GS-5885) & \\
\hline & Phase III & & & & GS-58I6 & \\
\hline & Phase II & GS-9857 & & GS-9669 & & \\
\hline & & Vedroprevir (GS-945I) & & Tegobuvir (GS-9|90)a & & \\
\hline & & GS-9256a & & & & \\
\hline \multirow[t]{3}{*}{ Janssen } & Approved & Telaprevir & & & & \\
\hline & & Simeprevir & & & & \\
\hline & Phase II & & & TMC-055 & GSK-2336805 & \\
\hline \multirow[t]{5}{*}{ Merck } & Approved & Boceprevir & & & & \\
\hline & Phase III & Grazoprevir (MK-5I72) & & & Elbasvir (MK-8742) & \\
\hline & & Vaniprevir (MK-7009) ${ }^{\mathrm{a}}$ & & & & \\
\hline & Phase II & & MK-3682 (IDX-437) & MK-8876 & MK-8408 & \\
\hline & & & MK/IDX-459 & & Samatasvir (IDX-7|9) & \\
\hline Debiopharm & Phase II & & & & & Alisporivir \\
\hline Roche & Phase III & Danoprevir (RG-7227) & Mericitabine (RG-72I8) & Setrobuvir (ANA-598) ${ }^{\mathrm{a}}$ & & \\
\hline Santaris & Phase II & & & & & Miravirsen \\
\hline Vertex & Phase II & $V X-135^{b}$ & & & & \\
\hline
\end{tabular}

Notes: aDenotes direct-acting antiviral agents which have been discontinued; benotes direct-acting antiviral agents currently on hold.

RAVs with preserved replication fitness emerge rapidly to become dominant (eg, R155K in the context of telaprevir).

\section{NS3/4A protease inhibitors}

NS3/4A protease inhibitors (PIs) block the catalytic site of the NS3/4A protease, resulting in failure of polyprotein cleaving and processing. The first DAAs to be developed and licensed for the treatment of HCV genotype 1 (HCV-1) were the NS3/4A PIs, telaprevir, and boceprevir. While offering a significant improvement in sustained virological response rates (SVRs) for HCV-1, these agents require combination with PR and had significant additional toxicity to PR, a large daily pill burden, and significant DDIs. Simeprevir (SMV), a second-wave first-generation NS3/4A PI with a more favorable pharmacokinetic profile allowing once daily dosing, with less additional toxicity on top of PR therapy and improved genotype coverage, has since been developed and has largely replaced telaprevir and boceprevir. Second-generation NS3/4A PIs are currently in development that offer the advantages of higher potency and improved adverse event (AE) profiles, while still allowing daily dosing. Furthermore, the second-generation PIs have an even wider activity against other genotypes and also have activity against RAVs that confer resistance to telaprevir and boceprevir.

\section{NS5B polymerase inhibitors}

The NS5B polymerase is highly conserved across all HCV genotypes, and thus is an ideal target for DAA development. NS5B polymerase inhibitors are divided into two types: nucleos $(\mathrm{t})$ ide NS5B inhibitors and nonnucleos(t)ide NS5B inhibitors.

\section{Nucleos(t)ide NS5B inhibitors}

Nucleos(t)ide analogs of the NS5B polymerase act as chain terminators within the catalytic site of the NS5B polymerase (nucleotide inhibitors [NIs]). These agents provide a high genetic barrier to resistance, have pangenotypic activity (as the NSB5 polymerase is highly conserved), high potency, and limited DDIs, and offer daily dosing. SOF is the only NI that has reached the market to date. The development of a number 
of NIs has been terminated due to toxicity; however, a number of promising NIs are currently in Phase II/III development.

\section{Nonnucleos(t)ide NS5B inhibitors}

These agents bind to different allosteric sites of the NS5B polymerase, which result in conformational changes, rendering the polymerase ineffective. These domains are highly variable between genotypes, and hence these agents only have activity against HCV-1. This class of agents also has a low barrier to resistance.

\section{NS5A inhibitors}

The NS5A protein has multiple functions and is important in viral replication and assembly. Inhibitors of the NS5A protein have been shown to be potent antivirals, although the exact mechanism by which these agents interact with the NS5A protein and inhibit HCV replication remains unclear. Three NS5A inhibitors have now been licensed for HCV-1, including daclatasvir (DCV), ledipasvir (LDV), and ombitasvir (OBV). DCV has broader genotypic activity and is the only NS5A inhibitor licensed for genotype $3 \mathrm{HCV}$ (HCV-3). Secondgeneration NS5A inhibitors are in development, which have broader genotypic activity, increased antiviral efficacy, and an improved genetic barrier to resistance.

\section{Host-targeting agents}

$\mathrm{HCV}$ interacts with a number of host cellular proteins and RNAs that promote viral replication. Host targets for drug development include cyclophilin A (alisporivir ${ }^{11-13}$ ) and miR122 (miravirsen ${ }^{14}$ ). Novel immunomodulators, including toll-like receptor agonists, have also entered the early phase of clinical development. However, the clinical role of these agents in the context of the highly effective, well-tolerated DAA regimens that have recently been licensed is not clear, and they will not be discussed further.

\section{HCV genotype I: approved interferon-free combinations}

\section{Sofosbuvir + ledipasvir}

The combination of SOF (NI) and LDV (NS5A inhibitor) has been licensed for treatment-naïve and treatment-experienced patients with HCV-1 (Tables 2 and 3). These DAAs are coformulated as a fixed dose combination tablet administered once daily.

\section{Treatment-naïve HCV-I patients with and} without cirrhosis: SVR I $2=93 \%-100 \%$ ION $1^{15}$ and ION $3^{16}$ examined SOF + LDV in treatmentnaïve patients. Patients with $\mathrm{ION} 1$ received SOF $+\mathrm{LDV} \pm$ ribavirin (RBV) for 12 weeks or 24 weeks. ${ }^{15}$ Sixteen percent of patients with compensated cirrhosis were included. The overall SVR12 was $97 \%-99 \%$ for the SOF + LDV \pm RBV 12-week arms and 98\%-99\% for the SOF + LDV \pm RBV 24-week arms. These data suggest that 12 weeks is sufficient for treatment-naïve patients, and that RBV is not required for this regimen. Traditional factors associated with PR treatment failure did not affect SVR12 rates. Treatment was well tolerated, and serious AEs were infrequent. The most common AEs were fatigue, headache, insomnia, and nausea $(>10 \%$ for each) and were more common in the RBV arms. Anemia was seen exclusively in patients receiving RBV. Virological breakthrough was observed in one patient, and this was attributed to nonadherence, as drug levels of LDV and the active metabolite were undetectable.

ION3 was a noninferiority study comparing SOF + $\mathrm{LDV} \pm \mathrm{RBV}$ for 8 weeks to SOF $+\mathrm{LDV}$ for 12 weeks. ${ }^{16}$ Treatment-naïve patients without cirrhosis were included. Overall SVR12 was 94\% in the SOF + LDV 8-week arm, $93 \%$ in the SOF + LDV + RBV 8-week arm, and 95\% in the SOF + LDV 12-week arm. When stratified by fibrosis stage, HCV-1 subtype and IL28B genotype, there was no difference in SVR12. High pretreatment viral load has been previously associated with lower SVR rates with PR. When patients were stratified according to baseline HCV RNA level, patients with a lower baseline viral load ( $<6$ million $\mathrm{IU} / \mathrm{mL}$ ) had similar SVR12 rates irrespective of duration of therapy (SVR12 97\% for 8-weeks SOF + LDV \pm RBV vs SVR12 96\% for 12-weeks SOF + LDV). However, in those with a baseline $\mathrm{HCV}$ RNA $\geq 6$ million IU/mL, relapse rates were significantly higher in the 8-week arm compared to the 12-week arm $(10 \%$ vs $1 \%$ for $\mathrm{HCV}$ RNA IU/mL $<6$ million $\mathrm{IU} / \mathrm{mL}$ and $\geq 6$ million $\mathrm{IU} / \mathrm{mL}$ in the 8 -week arm vs $1 \%$ for the 12-week arm irrespective of baseline viral load). ${ }^{17}$ These data suggest that 8 weeks of therapy is sufficient in noncirrhotic HCV-1 treatment-naïve patients, with a baseline HCV RNA level of $<6$ million IU/mL; however, patients with higher baseline HCV RNA levels benefit from extending therapy to 12 weeks, which has important economic implications with these expensive regimens. AEs were similar to the ION1 study. The S282T RAV, which confers resistance to SOF, was not detected in patients who failed therapy in the ION1 or ION3 studies; however, treatment-emergent NS5A RAVs were detected in the majority at the time of failure.

\section{Treatment-experienced patients with HCV-I} with and without cirrhosis, including prior protease inhibitor failure: SVR I $2=94 \%-99 \%$ ION2 investigated SOF + LDV \pm RBV for 12 weeks or 24 weeks in patients with prior PR or PR plus a 


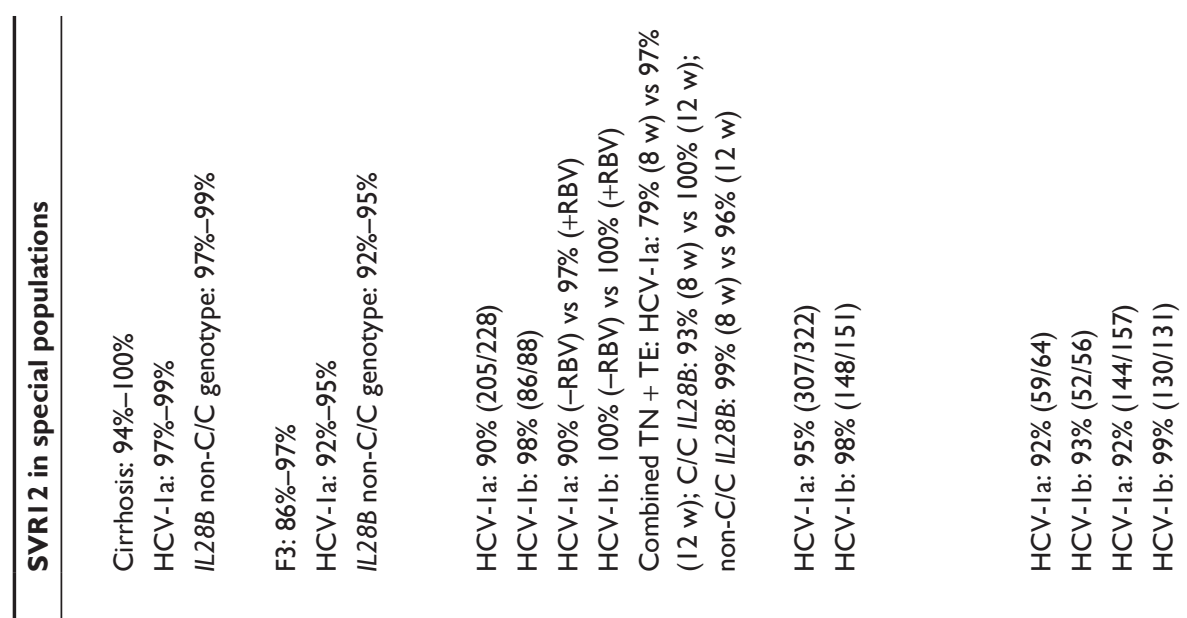

ARER

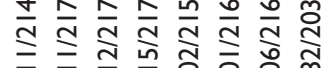

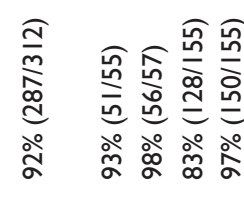

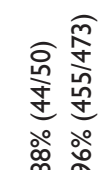

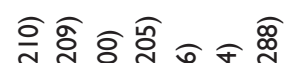

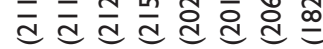

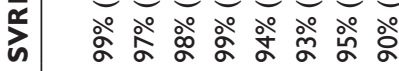

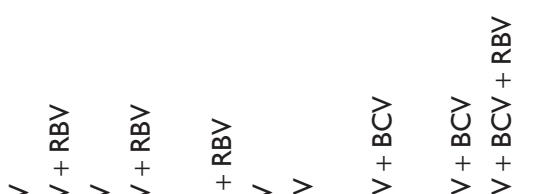

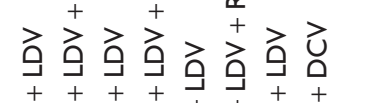

方至 $\sum_{i=}^{+}$

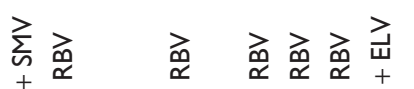

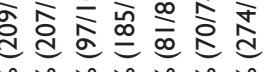

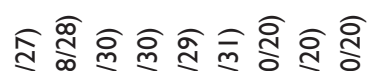

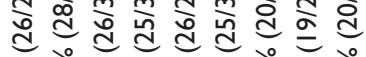

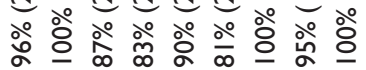

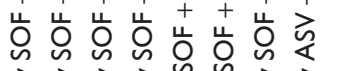

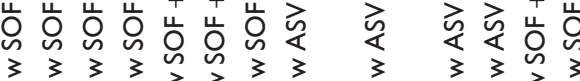

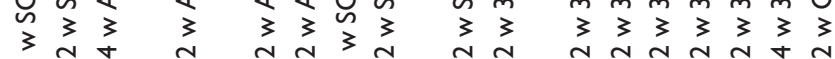

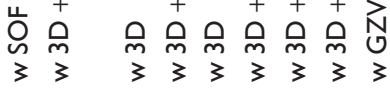

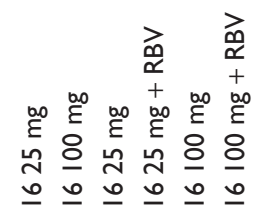

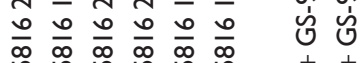

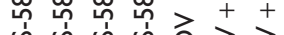

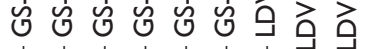
+
+
+ 岁茛 $\begin{array}{lllllllllll}3 & 3 & 3 & 3 & 3 & 3 & 3 & 0 & 0 \\ 0 & 3 & 3\end{array}$

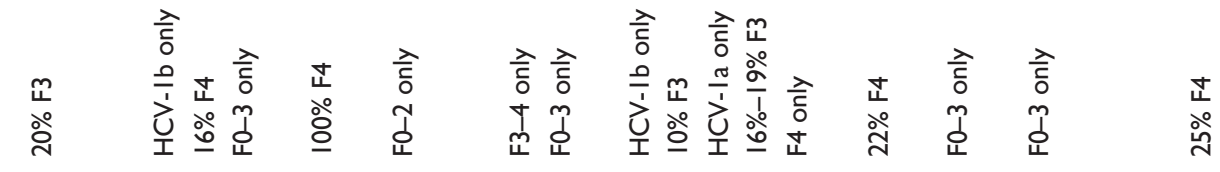

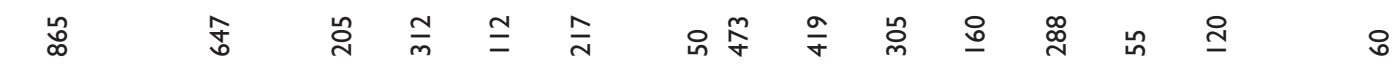

(n)

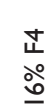
$\simeq \simeq$ $\simeq \simeq \simeq \simeq \simeq$

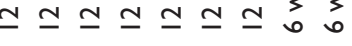




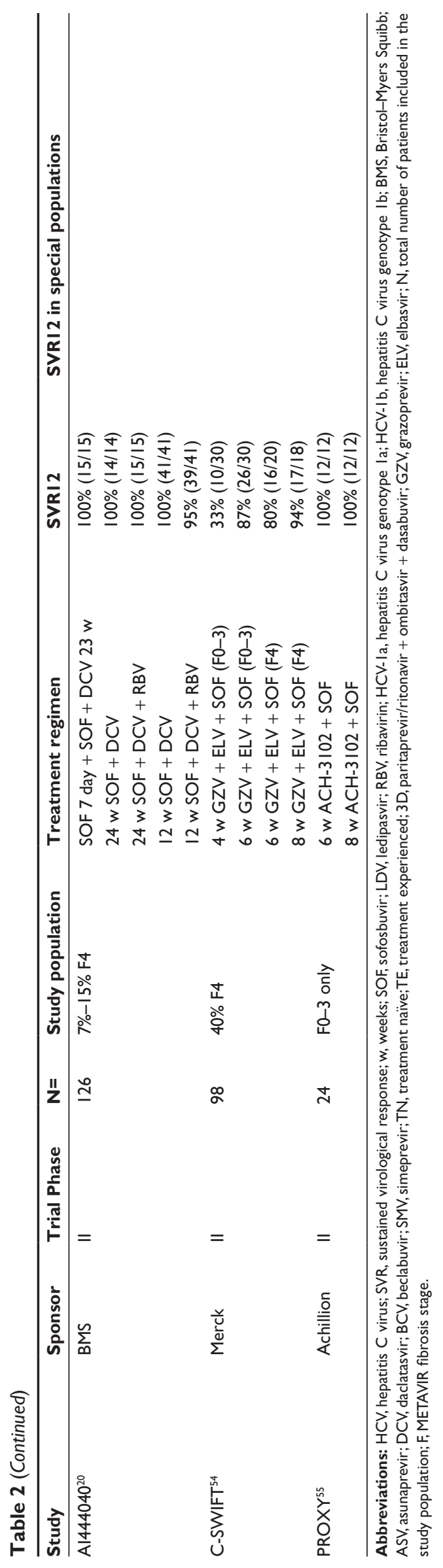

first-generation PI (telaprevir or boceprevir) failure. ${ }^{18,19}$ Patients were randomized to receive SOF $+\mathrm{LDV} \pm \mathrm{RBV}$ for 12 weeks or SOF $+\mathrm{LDV} \pm \mathrm{RBV}$ for 24 weeks. Patients with compensated cirrhosis $(20 \%)$ were included. The majority carried the poor-responder $I L 28 B$ genotype and the HCV-1a subtype, and $46 \%-61 \%$ had previously failed PIs. Overall SVR12 rates were similar to treatment-naïve populations with an SVR 12 of $94 \%-96 \%$ for the SOF + LDV \pm RBV 12-week groups and $99 \%$ for the SOF + LDV \pm RBV 24-week groups. SVR12 rates were similar in patients who had failed PR (93\%-100\%) and those who failed PR + PI (94\%-100\%). However, SVR 12 rates were significantly lower in cirrhotics treated for 12 weeks ( $82 \%-86 \%$ ) compared to $100 \%$ for the 24-week arms. The S282T RAV was not detected at treatment failure, but treatment-emergent NS5A RAVs were again detected in the majority. These data demonstrate that LDV + SOF is highly effective in patients with HCV-1, including prior treatment failure with first-generation PIs; however, 24 weeks of therapy is likely required for cirrhotic treatment-experienced patients.

In a post hoc analysis of the Phases II and III programs of all patients with HCV-1 with compensated cirrhosis (treatment naïve and treatment experienced) and receiving SOF + LDV \pm RBV, overall SVR12 rates were $96 \%$, with SVR 12 rates of $95 \%$ in patients receiving 12 -week regimens and $98 \%$ for $24-w e e k$ regimens. However, when the analysis was limited to treatment-experienced patients with compensated cirrhosis, SVR12 rates were lower in patients who received SOF + LDV without RBV for 12 weeks (SVR12 90\%). The addition of RBV to the 12-week SOF + LDV regimen increased SVR12 rates to $96 \%$, which was identical to the SVR12 rates in patients receiving 24-weeks of SOF + LDV dual therapy. These data suggest that SOF + LDV dual therapy for 12 weeks is insufficient in treatment-experienced cirrhotic patients, and that these patients benefit either from the addition of RBV to the 12-week regimen or by the extension of therapy to 24 weeks to improve SVR 12 rates, which yielded similar but equivalent SVR12 rates. This has economic implications in clinical practice, as the addition of RBV to the 12-week regimen is likely to significantly reduce the cost of therapy compared to the cost of 24 weeks of SOF + LDV.

\section{Sofosbuvir + daclatasvir}

DCV is a first-in-class pangenotypic NS5A inhibitor that has been approved in Europe and Japan. DCV has recently been licensed in the US, with the label indication for HCV-3 only. There are limited small Phase II/III studies on this combination; the majority in patients with $\mathrm{HCV}-2 / 3$ where 


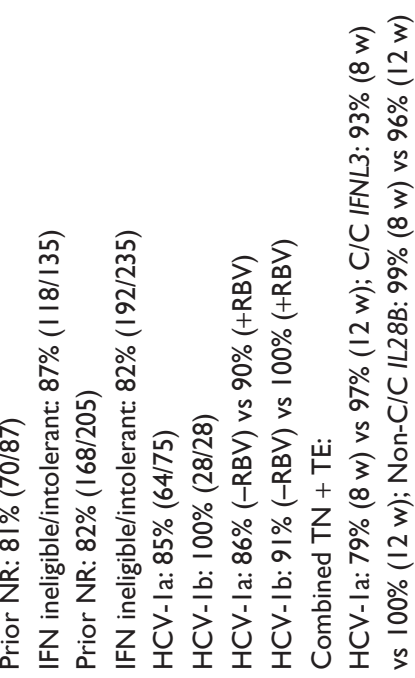

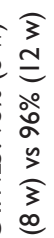

บั

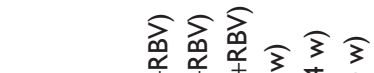

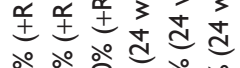

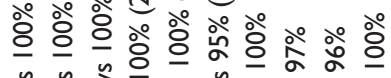

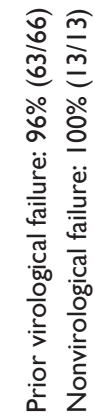

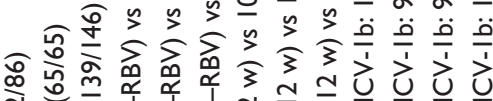

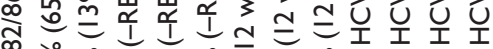

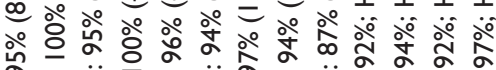

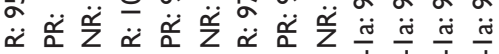

흔 흔 흘 흔 흔 흔 흔 흔 흔

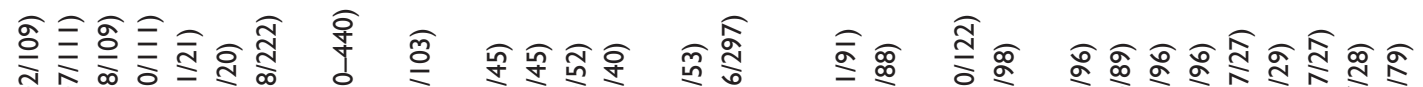

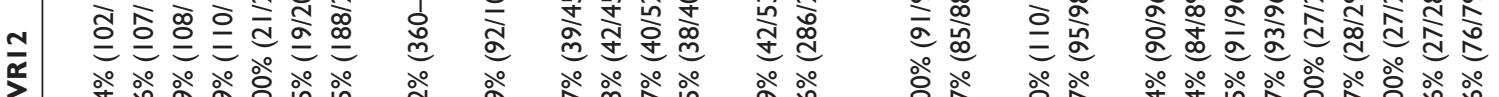

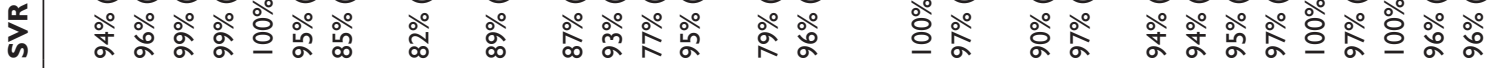

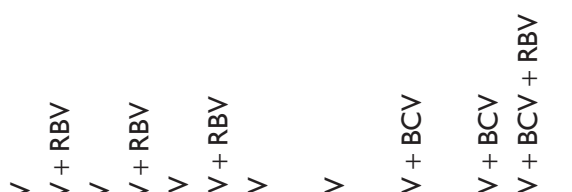

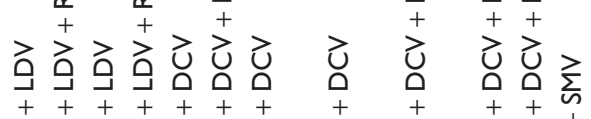

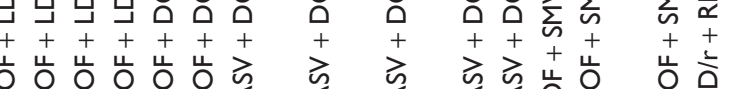

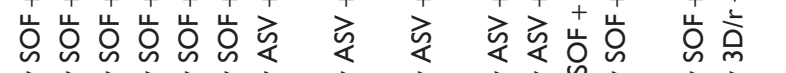

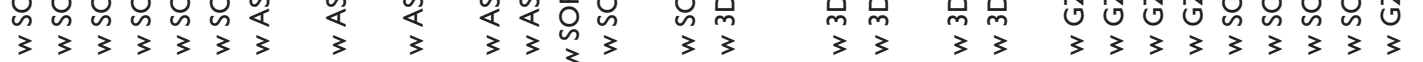

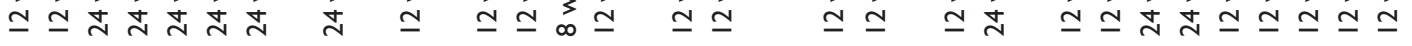

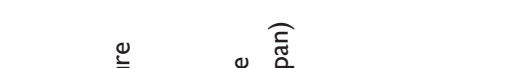

\section{高}

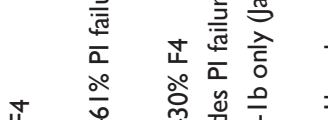

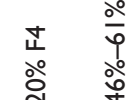

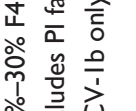

过高主

文

ते

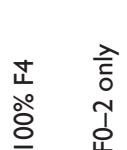

言

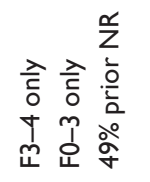

空

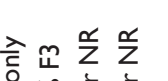

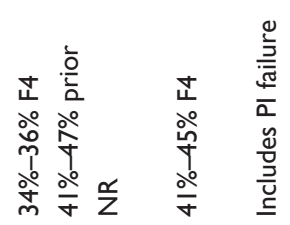

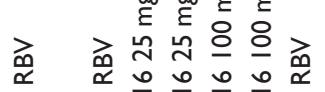

$+>++>$ 市

चु山्ठ

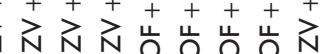

$\bar{ส}$ ส

กิ ลิ

$\stackrel{\infty}{\circ}$

$\stackrel{\infty}{\infty}$

สิ

$\underset{m}{\stackrel{N}{m}}$

$\equiv$

3
वे
व
+ 
DCV has superior potency compared to other licensed NS5A inhibitors such as LDV.

\section{Treatment-naïve HCV-I patients}

with and without cirrhosis: SVR I $2=95 \%-100 \%$

The AI444040 study investigated SOF + DCV \pm RBV for 24 weeks RBV in treatment-naïve patients with $\mathrm{HCV}-1$ and $\mathrm{HCV}-2 / 3 .{ }^{20}$ The study was later expanded to include a larger cohort of treatment-naïve patients, prior first-generation PI failure, and SOF + DCV \pm RBV 12-week arms were added. Treatment-naïve patients with $\mathrm{HCV}-1$ were randomized to $\mathrm{SOF}+\mathrm{DCV} \pm \mathrm{RBV}$ for 12 weeks or 24 weeks. The study population included patients with significant fibrosis (7\%-15\% compensated cirrhosis), and the majority were infected with HCV-1a. SVR 12 rates were $100 \%$ for the 24 -week arms and $95 \%-100 \%$ for the 12 -week arms. The regimen was very well tolerated with the majority of AEs graded mild in severity. The most common AEs were headache (16\%-38\%), fatigue (29\%-50\%), and nausea (16\%-32\%) and were more common in the RBV-containing arms.

Treatment-experienced patients with HCV-I with and without cirrhosis, including prior protease inhibitor failure: SVR I $2=95 \%-100 \%$

The AI444040 study also included patients with HCV-1 who had previously failed telaprevir or boceprevir plus $\mathrm{PR} .{ }^{20}$ The patients received $\mathrm{SOF}+\mathrm{DCV} \pm \mathrm{RBV}$ for 24 weeks. The majority had the poor-responder IL28B genotype (95\%), and $14 \%-30 \%$ had compensated cirrhosis. The SVR 12 rates were $100 \%$ for the 24-week SOF + DCV arm and 95\% (19/20) for the $\mathrm{SOF}+\mathrm{DCV}+\mathrm{RBV}$ arm. The AE profile was very similar to that observed in treatment-naïve patients.

\section{Sofosbuvir + simeprevir}

SOF and SMV were the first DAAs licensed separately in North America based on data demonstrating efficacy as triple therapy with PR. The COSMOS study, ${ }^{21}$ a small Phase II study, subsequently showed that the combination of SOF + SMV was highly effective. This off-label combination was the first IFNfree treatment regimen widely prescribed for HCV-1 in North America. Phase III programs have subsequently confirmed efficacy, and now the combination has a label.

\section{Treatment-naïve and treatment-experienced} patients with HCV-I without significant fibrosis: SVR I $2=87 \%-97 \%$

OPTIMIST $-1^{22}$ and OPTIMIST- $2^{23}$ evaluated the efficacy of SOF + SMV \pm RBV in treatment-naïve and treatment-experienced patients. OPTIMIST-1 enrolled patients with mild-moderate liver fibrosis (METAVIR F0-224), whereas OPTIMIST-2 only included patients with advanced fibrosis (METAVIR F3-4). OPTIMIST- $1^{22}$ compared 8 weeks vs 12 weeks of SOF + SMV in treatment-naïve and treatment-experienced patients with noncirrhotic $\mathrm{HCV}-1$. The majority carried the poor-responder $I L 28 B$ genotype and were HCV-1a. The SVR12 for the 8-week group was significantly lower than the 12 -week group ( $83 \%$ vs $97 \%$ ), particularly in treatment-experienced patients, where the SVR 12 was $77 \%$. In the 12-week arm, there was no difference in SVR according to HCV-1 subtype or $I L 28 B$ genotype. SOF + SMV was well tolerated, with the majority of AEs being mild. Headache, fatigue, and nausea were most commonly reported. AEs of special interest with this regimen were a mild elevation of bilirubin (1\%) not associated with transaminitis, due to the known inhibition of the organic anion-transporting polypeptide bilirubin transporter and photosensitivity/rash in $10 \%$.

Treatment-naïve and treatment-experienced patients with significant fibrosis: SVR I $2=79 \%-88 \%$

In OPTIMIST-2, ${ }^{23}$ treatment-naïve and treatment-experienced patients with advanced liver fibrosis (METAVIR F3-4) and compensated liver disease were treated with SOF + SMV for 12 weeks. Similar to OPTIMIST-1, the majority of patients carried the poor-responder IL28B genotype, had HCV-1a infection, and $49 \%$ were treatment naïve. The overall SVR12 rate was $84 \%$. The SVR12 in treatment-naïve patients was $88 \%$ and was lower in treatment-experienced patients $(79 \%)$. AEs were similar to those observed in OPTIMIST-1, with headache, fatigue, and nausea being the predominant side effects.

\section{Paritaprevir/ritonavir, ombitasvir, dasabuvir \pm RBV}

The paritaprevir/ritonavir + ombitasvir + dasabuvir (3D) regimen includes 3 DAAs: paritaprevir ([PTV], a PI that requires ritonavir boosting), OBV (NS5A inhibitor), and dasabuvir ([DSV], a nonnucleos(t)ide inhibitor [NNI]). It is used in combination with RBV in patients with $\mathrm{HCV}-1 \mathrm{a}$. The regimen is approved in the US and Europe.

\section{Treatment-naïve HCV-I patients} without cirrhosis: SVR I $2=90 \%-97 \%$

The SAPPHIRE-I ${ }^{25}$ study evaluated the efficacy of the $3 \mathrm{D}$ regimen for 12 weeks $\pm \mathrm{RBV}$ in treatment-naïve patients with $\mathrm{HCV}-1 \mathrm{a} / 1 \mathrm{~b}$ without cirrhosis. This study included 473 patients, 68\% with HCV-1a and 30\% with the 
good-responder IL28B genotype. Separate studies examined the role of RBV for patients with noncirrhotic HCV-1b and HCV-1a, respectively: PEARL-III enrolled patients with noncirrhotic HCV-1b (21\% C/C IL28B genotype) and PEARL-IV enrolled patients with $\mathrm{HCV}-1 \mathrm{a}\left(31 \% \mathrm{C} / \mathrm{C}\right.$ IL $28 B$ genotype). ${ }^{26}$ In noncirrhotic treatment-naïve patients with $\mathrm{HCV}-1 \mathrm{a}$, combined SVR12 rates from these studies were 95\%-97\% with the 3D + RBV 12-week regimen, but slightly lower SVR12 rates were observed without RBV (90\%) (Table 2). For the patients with HCV-1b, SVR12 rates were 98\%-100\% irrespective of whether RBV was administered (Table 2).

\section{Treatment-naïve HCV-I patients with cirrhosis: SVR $12=94 \%-95 \%$}

The TURQUOISE-II study was a large study of cirrhotic patients. ${ }^{27}$ In treatment-naïve compensated cirrhotics, the efficacy of the $3 \mathrm{D}+\mathrm{RBV}$ regimen was compared for 12 weeks or 24 weeks (Table 2). Very high SVR12 rates were observed in both the 3D + RBV 12-week (94\%) and the 3D + RBV 24-week (95\%) treatment arms. The 3D \pm $\mathrm{RBV}$ regimen was well tolerated in treatment-naïve patients and similar AEs were reported in patients with and without cirrhosis. The most common AEs were headache (23\%-28\%), fatigue $(21 \%-46 \%)$, nausea $(4 \%-21 \%)$, pruritus $(5 \%-12 \%)$, insomnia (3\%-17\%), and diarrhea $(4 \%-16 \%)$. Anemia was observed only in patients receiving RBV.

\section{Treatment-experienced patients}

with HCV-I without cirrhosis: SVR I $2=94 \%-100 \%$

$3 \mathrm{D}+\mathrm{RBV}$ for 12 weeks was examined in noncirrhotic treatment-experienced patients without cirrhosis. In SAPPHIRE-II, ${ }^{28}$ 173 patients with HCV-1a were enrolled, and 124 patients with $\mathrm{HCV}-1 \mathrm{~b}$ were enrolled. The majority were prior null responders (49\%) and carried the poor-responder IL28B genotype. PEARL-II ${ }^{29}$ enrolled 186 patients with HCV-1b. Prior null responders represented $35 \%$ of the study population. Combined SVR12 rates from both studies were extremely high in this difficult to treat population, with SVR12 rates of $96 \%$ for $\mathrm{HCV}-1 \mathrm{a}$ and $97 \%-100 \%$ for HCV-1b, with and without RBV. Past treatment history did not affect treatment responses, with SVR12 rates of $94 \%-100 \%$ in prior null responders, $96 \%-100 \%$ in prior partial responders, and $100 \%$ in prior relapsers (Table 3 ).

\section{Treatment-experienced patients with HCV-I with cirrhosis: SVRI $2=94 \%-100 \%$}

For the treatment-experienced cirrhotic patients, the 3D+ $\mathrm{RBV}$ regimen for 12 weeks was compared to 24 weeks. ${ }^{27}$ The study population $(\mathrm{n}=220$ ) included $69 \%$ with $\mathrm{HCV}-1 \mathrm{a}$,
$89 \%$ carried the non-C/C IL28B genotype, and 62\% were prior null responders to PR therapy. Overall, the SVR12 rate in patients with $\mathrm{HCV}-1$ a was lower in the 12-week arm compared to the 24 -week arm (89\% vs 94\%, respectively). In contrast, SVR12 rates were similar in the 12- and 24-week arms (99\% and 100\%, respectively) in patients with $\mathrm{HCV}-1 \mathrm{~b}$. $\mathrm{HCV}-1$ a prior null responder cirrhotic patients benefited from the longer treatment duration ( $80 \%$ vs $93 \%$ for the 12 -week compared to the 24-week regimens, respectively, Table 3 ). Hence, 24 weeks has been recommended in $\mathrm{HCV}$-1a prior null responder patients with cirrhosis. AEs were very similar to those reported in treatment-naïve patients.

\section{Asunaprevir + daclatasvir}

Asunaprevir (ASV) is a second-wave first-generation NS3/4A PI. The combination of ASV plus DCV has been licensed for the treatment of patients with HCV-1b only. This combination is less effective in patients with $\mathrm{HCV}-1$ a due to the low genetic barrier to resistance and high failure rate, and therefore is not recommended for the treatment of this subtype. ${ }^{30}$

\section{HCV-Ib treatment-naïve and treatment-experienced} patients with and without cirrhosis: SVR I $2=81 \%-90 \%$ Two Phase III studies have evaluated ASV + DCV for 24 weeks in patients with HCV-1b. The first was a study in Japanese patients with $\mathrm{HCV}-1 \mathrm{~b}$ who were prior nonresponders or interferon intolerant/ineligible, including patients with compensated cirrhosis. ${ }^{31}$ SVR12 rates were lower in the prior nonresponders ( $81 \%$ ) compared to patients who were interferon intolerant/ineligible (88\%). SVR12 rates were similar among patients with and without cirrhosis. The second study was a multinational study that evaluated ASV + DCV for 24 weeks in patients with $\mathrm{HCV}-1 \mathrm{~b}$ who were treatment naïve, prior null responders, or interferon intolerant/ineligible. ${ }^{32}$ Patients with compensated cirrhosis were included in all three groups. The overall SVR12 rates were $90 \%$ for treatment-naïve patients, $82 \%$ for prior nonresponders, and $82 \%$ for the interferon intolerant/ineligible group and were similar in patients with and without cirrhosis. Serious AEs were uncommon, and the most commonly reported AEs were headache, diarrhea, and asthenia (Tables 2 and 3).

\section{HCV genotype I: regimens in Phase III clinical development Grazoprevir + elbasvir}

Grazoprevir (GZV) is a second-generation NS3/4A PI that has activity against the RAVs that emerge during treatment with telaprevir and boceprevir. Elbasvir (ELV) is a second-generation 
NS5A inhibitor with pangenotypic activity. This combination has been evaluated in Phase III studies in treatment-naïve and treatment-experienced patients with $\mathrm{HCV}-1, \mathrm{HCV}-4$, and HCV-6 (C-EDGE), ${ }^{33,34}$ including prior PI failures (C-SALVAGE) ${ }^{35}$

\section{Treatment-naïve patients with HCV-I}

with and without cirrhosis: SVR I $2=92 \%-99 \%$

GZV + ELV for 12 weeks were evaluated in treatment-naïve patients (C-EDGE).$^{34}$ This population included $22 \%$ patients with compensated cirrhosis and 55\% with HCV-1a infection. SVR12 rates were very high, with an overall SVR12 of 95\%; $92 \%$ in HCV-1a and $99 \%$ in HCV-1b. IL28B genotype and fibrosis stage did not impact upon SVR12. The AE profile of this regimen was again favorable. The AEs reported were headache, fatigue, and nausea and were similar in patients with and without cirrhosis.

Treatment-experienced patients with HCV-I with and without cirrhosis, including prior protease inhibitor failure: SVR I $2=90 \%-100 \%$

The C-EDGE study also enrolled prior PR treatmentexperienced patients with and without compensated cirrhosis. ${ }^{34}$ Patients were randomized to receive GZV + ELV $\pm \mathrm{RBV}$ for 12 weeks or 16 weeks. The majority were HCV-1a, and $35 \%$ had compensated cirrhosis. Overall SVR12 rates were universally high (92\%-97\%), but were slightly lower in patients with HCV-1a (90\%-93\% for the 12-week arms and 94\%-95\% for the 16-week arms) compared to patients with HCV-1b (97\%-100\% for the 12-week arms and 96\%-100\% for the 16-week arms). The SVR12 rates in cirrhotics were also lower in the 12-week arm compared to the 16-week arm (89\% vs 92\%-100\%, respectively). Prior PR null responders achieved SVR12 rates of $91 \%$ in the 12-week arms and $94 \%-100 \%$ in the 16 -week arms (Table 3). In this particular regimen, the presence of baseline NS5A RAVs in patients with $\mathrm{HCV}-1$ a that resulted in a $\geq 5$-fold reduction in susceptibility to ELV negatively impacted on SVR12 (52\%). This regimen was well tolerated with few serious AEs, and the majority of AEs comprised of fatigue, headache, and nausea.

In C-SALVAGE, 79 patients with $\mathrm{HCV}-1$ with prior PI failure (null responders or intolerance) were included. ${ }^{35}$ Patients with HCV-1a comprised $38 \%$ of the cohort, $43 \%$ had compensated cirrhosis, and $84 \%$ were prior null responders to PI-based PR therapy. Despite these difficult to treat baseline characteristics, the overall SVR12 was 96\%: 96\% with prior protease-inhibitor PR therapy failure and $100 \%$ in patients intolerant to PI-based PR therapy. The AE profile was identical to that observed in the C-EDGE studies (Table 3).

\section{Asunaprevir + daclatasvir + beclabuvir \pm RBV}

This triple DAA combination of ASV + DCV combined with the NNI beclabuvir (BCV) has been examined in Phase III studies in patients with HCV-1. ${ }^{36,37}$ Overall SVR12 rates were $92 \%$ for treatment-naïve patients without cirrhosis, $93 \%-98 \%$ in treatment-naïve patients with cirrhosis, and $85 \%-91 \%$ in treatment-experienced patients with and without cirrhosis. Efficacy was high in patients with $\mathrm{HCV}-1 \mathrm{~b}$ irrespective of prior treatment status and fibrosis stage. As observed in the ASV + DCV dual therapy study, SVR12 rates were noted to be suboptimal in HCV-1a compared to the patients with HCV-1b. In particular, the lowest SVR12 rates were observed in treatment-naïve $\mathrm{HCV}-1 \mathrm{a}$ patients with cirrhosis and a platelet count of $<100,000$ cells $/ \mathrm{mm}^{3}$, where SVR12 rates were as low as $87 \%$, and treatment-experienced patients with HCV-1a, where SVR12 rates were $85 \%-86 \%$ irrespective of fibrosis stage. Addition of RBV to the regimen did improve SVR12 rates in cirrhotic patients (Tables 2 and 3). A larger Phase III study (UNITY-4) is currently underway enrolling patients with $\mathrm{HCV}-1$, with and without cirrhosis to further evaluate this regimen. The safety profile of this regimen was similar to other IFN-free combinations.

\section{HCV genotype 3: approved interferon-free combinations}

Table 4 summarizes the clinical trial results for IFN-free regimens in patients with $\mathrm{HCV}-3$. $\mathrm{HCV}-3$, particularly treatment-experienced patients with cirrhosis, has rapidly emerged as the most difficult to treat population with IFNfree DAA combinations.

\section{Sofosbuvir + RBV}

This regimen was extremely promising in Phase II; however, in the Phase III studies, this regimen proved less effective, particularly in the cirrhotic population. The Phase III studies (FISSION, FUSION, and VALENCE) will be discussed.

\section{Treatment-naïve patients with HCV-3}

with and without cirrhosis: SVR I $2=56 \%-95 \%$

FISSION $^{38}$ and VALENCE ${ }^{39}$ examined the efficacy of SOF + RBV in patients with HCV-3. In FISSION, patients with HCV-3, 20\% with compensated cirrhosis, were treated with $\mathrm{SOF}+\mathrm{RBV}$ for 12 weeks. The SVR12 rate was disappointing at $56 \%$ and was lower than the group who received PR therapy (SVR12 63\%). ${ }^{38}$ This led to the VALENCE study, where the efficacy of longer duration of therapy was examined ( 24 weeks of SOF + RBV) in patients with HCV-3. ${ }^{39}$ 
Table 4 Interferon-free regimens for HCV genotype 3 treatment-naïe and treatment-experienced patients

\begin{tabular}{|c|c|c|c|c|c|c|c|}
\hline Study & Sponsor & Trial Phase & $\mathbf{N}=$ & $\begin{array}{l}\text { Study } \\
\text { population }\end{array}$ & Treatment regimen & SVRI 2 & $\begin{array}{l}\text { SVRI } 2 \text { in special } \\
\text { populations }\end{array}$ \\
\hline \multicolumn{8}{|c|}{ HCV genotype 3 treatment-naïve patients } \\
\hline FISSION $^{38}$ & Gilead & III & 183 & $20 \% \mathrm{~F} 4$ & 12 w SOF + RBV & $56 \%(102 / 183)$ & \\
\hline \multirow[t]{2}{*}{ VALENCE $^{39}$} & Gilead & III & 105 & $20 \% \mathrm{~F} 4$ & 12 w SOF + RBV & $94 \%(99 / 105)$ & F0-3: 95\% (87/92) \\
\hline & & & & & & & F4: $92 \%(12 / 13)$ \\
\hline \multirow[t]{2}{*}{ ALLY-341 } & BMS & III & 101 & $19 \% \mathrm{~F} 4$ & 12 w SOF + DCV & $90 \%(91 / 101)$ & F0-3: $97 \%(73 / 75)$ \\
\hline & & & & & & & F4: $58 \%(11 / 19)$ \\
\hline \multirow[t]{2}{*}{ ELECTRON-2 $2^{42}$} & Gilead & II & 51 & $15 \% \mathrm{~F} 4$ & 12 w SOF + LDV & $64 \%(16 / 25)$ & \\
\hline & & & & & $12 \mathrm{wSOF}+\mathrm{LDV}+\mathrm{RBV}$ & $100 \%(26 / 26)$ & \\
\hline \multirow[t]{4}{*}{ ELECTRON-256 } & Gilead & II & 104 & F0-3 only & 8 w SOF + GS-58I6 $25 \mathrm{mg}$ & $100 \%(27 / 27)$ & \\
\hline & & & & & $8 \mathrm{w}$ SOF + GS-5816 $25 \mathrm{mg}+\mathrm{RBV}$ & $88 \%(21 / 24)$ & \\
\hline & & & & & 8 w SOF + GS-5816 $100 \mathrm{mg}$ & $96 \%(26 / 27)$ & \\
\hline & & & & & 8 w SOF + GS-5816 100 mg + RBV & $100 \%(26 / 26)$ & \\
\hline \multicolumn{8}{|c|}{ HCV genotype 3 treatment-experienced patients } \\
\hline \multirow[t]{2}{*}{ FUSION ${ }^{40}$} & Gilead & III & 127 & $34 \% \mathrm{~F} 4$ & 12 w SOF + RBV & $30 \%(19 / 64)$ & $\begin{array}{l}\text { F0-3: } 37 \%(12 w) \text { vs } \\
63 \%(16 \mathrm{w})\end{array}$ \\
\hline & & & & $25 \%$ prior NR & 16 w SOF + RBV & $62 \%(39 / 63)$ & $\begin{array}{l}\text { Cirrhosis: } 19 \%(12 w) \text { vs } \\
61 \%(16 w)\end{array}$ \\
\hline \multirow[t]{2}{*}{ VALENCE $^{39}$} & Gilead & III & 145 & $32 \% \mathrm{~F} 4$ & $24 \mathrm{w} S O F+\mathrm{RBV}$ & $79 \%(114 / 145)$ & F0-3: 87\% (85/98) \\
\hline & & & & & & & F4: $62 \%(9 / 13)$ \\
\hline \multirow[t]{2}{*}{ ELECTRON-2 ${ }^{42}$} & Gilead & II & 50 & $44 \% \mathrm{~F} 4$ & $12 \mathrm{w} S \mathrm{SOF}+\mathrm{LDV}+\mathrm{RBV}$ & $82 \%(4 I / 50)$ & F0-3: $89 \%(25 / 28)$ \\
\hline & & & & & & & F4: $73 \%(16 / 22)$ \\
\hline \multirow[t]{4}{*}{ SOF + GS-5816 $6^{57}$} & Gilead & II & 210 & $49 \% \mathrm{~F} 4$ & 12 w SOF + GS-5816 $25 \mathrm{mg}$ & $71 \%(37 / 52)$ & $85 \%(\mathrm{FO}-3)$ vs $58 \%(\mathrm{~F} 4)$ \\
\hline & & & & & $12 \mathrm{w}$ SOF + GS-5816 $25 \mathrm{mg}+\mathrm{RBV}$ & $91 \%(48 / 53)$ & $96 \%(\mathrm{~F} 0-3)$ vs $84 \%(\mathrm{~F} 4)$ \\
\hline & & & & & 12 w SOF + GS-5816 100 mg & $94 \%(50 / 53)$ & $100 \%(\mathrm{~F} 0-3)$ vs $88 \%(\mathrm{~F} 4)$ \\
\hline & & & & & $12 \mathrm{w}$ SOF + GS-5816 $100 \mathrm{mg}+\mathrm{RBV}$ & $98 \%(51 / 52)$ & $100 \%(\mathrm{~F} 0-3)$ vs $96 \%(\mathrm{~F} 4)$ \\
\hline
\end{tabular}

Abbreviations: HCV, hepatitis C virus; SVR, sustained virological response; w, weeks; SOF, sofosbuvir; RBV, ribavirin; BMS, Bristol-Myers Squibb; DCV, daclatasvir; LDV, ledipasvir; NR, null responder; N, number of patients included in the study population; F, METAVIR fibrosis stage.

The SVR12 was significantly higher with the longer treatment duration $\left(94 \%\right.$ in VALENCE ${ }^{39}$ vs $56 \%$ in FISSION $\left.{ }^{38}\right)$. When the analysis was stratified by fibrosis stage, the SVR12 rates were similarly high among treatment-naïve patients without cirrhosis (95\%) and with cirrhosis (92\%).

\section{Treatment-experienced patients with HCV-3}

with and without cirrhosis: SVR I $2=19 \%-87 \%$

However, the results in treatment-experienced patients were a little more disappointing. FUSION randomized patients with HCV-3 to receive either 12 weeks or 16 weeks of SOF + $\mathrm{RBV}^{40}$ The 12-week arm was inferior with overall SVR12 rates of only $30 \%$, but extending the treatment by $4-16$ weeks doubled SVR12 rates to $62 \%$. Even more striking was the impact of fibrosis stage on SVR12 results. For patients in the 12 -week arm, SVR12 rates were $37 \%$ for noncirrhotic patients and only $19 \%$ in cirrhotic patients. Extending the treatment to 16 weeks improved SVR 12 rates to $63 \%$ in noncirrhotics and $61 \%$ in cirrhotics. However, these results are still suboptimal compared to PR, especially considering the high cost of DAAs. Extending treatment beyond 16-24 weeks was examined in the VALENCE study, which enrolled HCV-3 treatment-experienced patients with and without cirrhosis. ${ }^{39}$ In this study, SVR12 rates were reasonable in treatmentexperienced patients without cirrhosis $(87 \%)$ but failed to improve SVR12 rates in treatment-experienced cirrhotics, where SVR 12 rates were still only $62 \%$, and similar SVR 12 was observed after 16 weeks in the FUSION study $(61 \%){ }^{40}$ This clearly identified HCV-3 treatment-experienced cirrhotic patients as the new hard-to-treat population that require better IFN-free regimens.

\section{Sofosbuvir + daclatasvir}

This IFN-free DAA combination is now approved in Europe and undergoing regulatory review in the US for the treatment of HCV-3. This regimen has been examined in ALLY-3, a Phase III study of SOF + DCV in treatmentnaïve and treatment-experienced patients with and without cirrhosis. $^{41}$

\section{Treatment-naïve patients with HCV-3 with and without cirrhosis: SVR I $2=58 \%-97 \%$}

In ALLY-3, treatment-naïve patients received 12 weeks of SOF + DCV. ${ }^{41}$ The treatment cohort included 19\% with 
compensated cirrhosis. The overall SVR12 was 90\%. When stratified according to fibrosis stage, SVR12 was very high in noncirrhotics $(97 \%)$, but fell to $58 \%$ in patients with cirrhosis. The AE profile was similar to that observed in patients with $\mathrm{HCV}-1$.

\section{Treatment-experienced patients with HCV-3} with and without cirrhosis: SVR I $2=69 \%-94 \%$

The ALLY-3 study also enrolled treatment-experienced patients, including patients who failed SOF + PR, SOF + $\mathrm{RBV}$, or the host targeting DAA, alisporivir. ${ }^{41}$ The overall SVR12 was similar to the treatment-naïve population at $86 \%$, but again a significantly lower SVR12 was observed in patients with cirrhosis (69\%) compared to patients without cirrhosis (94\%). This combination also highlights the HCV-3 cirrhotic population as a difficult-to-cure group.

\section{Sofosbuvir + ledipasvir \pm RBV}

SOF + LDV has been examined in treatment-naïve and treatment-experienced patients with HCV-3 in the ELECTRON-2 $2^{42,43}$ study, including patients with cirrhosis.

\section{Treatment-naïve patients with HCV-3}

with and without cirrhosis: SVR I $2=64 \%-100 \%$

Treatment-naïve patients, including cirrhotic patients (15\%), were randomized to receive either $\mathrm{SOF}+\mathrm{LDV} \pm \mathrm{RBV}$ for 12 weeks. ${ }^{42}$ SVR12 rates were superior with the addition of RBV (64\% for SOF + LDV vs 100\% SOF + LDV + RBV), highlighting the importance of $\mathrm{RBV}$ in this regimen.

\section{Treatment-experienced patients with HCV-3} with and without cirrhosis: SVRI $2=73 \%-89 \%$

The combination of SOF + LDV + RBV for 12 weeks was also examined in treatment-experienced patients, 44\% with compensated cirrhosis. ${ }^{43}$ The SVR 12 was $82 \%$ overall: $89 \%$ in noncirrhotics and $73 \%$ in patients with compensated cirrhosis, improving on previous IFN-free combination, highlighting a significant void in the management of these patients with IFN-free regimens.

\section{HCV genotype 2: approved interferon-free combinations}

Table 5 summarizes the Phase II/III IFN-free trials in HCV genotype 2 (HCV-2) patients. HCV-2 is increasingly being recognized as the easier to treat $\mathrm{HCV}$ genotype with both IFN-containing and IFN-free regimens. The majority of the first-generation PIs lack efficacy in $\mathrm{HCV}-2$, but the NIs and NS5A inhibitors are active against HCV-2 and have the largest body of supporting evidence regarding their utility in HCV-2. The currently approved regimens and Phase II/III data will be reviewed.

\section{Sofosbuvir + RBV}

The FISSION, ${ }^{38}$ POSITRON,${ }^{40}$ FUSION $^{40}$ and VALENCE ${ }^{39}$ Phase III studies examined the use of SOF + RBV in HCV-2 treatment-naïve and treatment-experienced patients. This combination is highly effective for patients with $\mathrm{HCV}-2$ and is recommended as first-line therapy in the European and American HCV treatment guidelines.

Treatment-naive patients with $\mathrm{HCV}-2$ with and without cirrhosis: SVR I $2=97 \%-100 \%$

FISSION ${ }^{38}$ compared SOF + RBV for 12 weeks to PR therapy for 24 weeks in 70 patients with HCV-2, including 20\% with compensated cirrhosis. SVR12 rates were very high $(97 \%)$ and superior to PR therapy (78\%). There was no significant difference in SVR12 when stratified according to fibrosis stage. VALENCE ${ }^{39}$ compared the efficacy SOF + RBV for 12 compared in patients with $\mathrm{HCV}-2$. Treatment-naïve patients achieved an SVR12 of 97\%. Only two patients with HCV-2 with cirrhosis were enrolled, and hence no meaningful comparison can be made between patients with and without cirrhosis. The safety profile was very similar to that observed in $\mathrm{HCV}-1$ patients.

\section{Treatment-experienced patients with HCV-2}

with and without cirrhosis: SVR $=68 \%-100 \%$ $\mathrm{SOF}+\mathrm{RBV}$ was examined in $\mathrm{FUSION}^{40}$ and VALENCE. ${ }^{39}$ FUSION $^{40}$ compared SOF + RBV for 12 weeks or 16 weeks in patients with $\mathrm{HCV}-2$. Cirrhotics were included (34\%) and $25 \%$ of the population were prior null responders. Overall SVR12 rates were lower in patients randomized to 12 weeks (86\%) compared to 16 weeks (94\%). Most notably, the lowest SVR12 rates were observed in cirrhotic patients in the 12-week arm (SVR12 60\% vs 96\% for cirrhotic and noncirrhotic patients in the 12 -week arms, and $78 \%$ vs $100 \%$ for cirrhotic and noncirrhotic patients in 16-week arms, respectively). A similar pattern of lower response in $\mathrm{HCV}-2$ cirrhotic treatment-experienced patients was also borne out in the VALENCE study, where the SVR12 rates were $78 \%$ in treatment-experienced patients with $\mathrm{HCV}-2$ with cirrhosis and $94 \%$ in treatment-experienced patients with HCV-2 without cirrhosis after 12 weeks of SOF + RBV. ${ }^{39}$ These data suggest that $\mathrm{HCV}-2$ treatment experienced patients with cirrhosis may benefit from extended therapy to 16 weeks. 
Table 5 Interferon-free regimens for HCV genotype 2 treatment-naïe and treatment-experienced patients

\begin{tabular}{|c|c|c|c|c|c|c|c|}
\hline Study & Sponsor & $\begin{array}{l}\text { Trial } \\
\text { Phase }\end{array}$ & $\mathbf{N}=$ & $\begin{array}{l}\text { Study } \\
\text { population }\end{array}$ & $\begin{array}{l}\text { Treatment } \\
\text { regimen }\end{array}$ & SVRI 2 & $\begin{array}{l}\text { SVRI } 2 \text { in special } \\
\text { populations }\end{array}$ \\
\hline \multicolumn{8}{|c|}{ HCV genotype 2 treatment-naïve patients } \\
\hline FISSION $^{38}$ & Gilead & III & 70 & $20 \% \mathrm{~F} 4$ & $12 w S O F+R B V$ & $97 \%(68 / 70)$ & \\
\hline \multirow[t]{2}{*}{ VALENCE $^{39}$} & Gilead & III & 32 & $20 \% \mathrm{~F} 4$ & 12 w SOF + RBV & $97 \%(31 / 32)$ & F0-3: 97\% (29/30) \\
\hline & & & & & & & F4: $100 \%(2 / 2)$ \\
\hline \multirow[t]{3}{*}{ Al $444040^{20}$} & BMS & II & 18 & $7 \%-15 \%$ F4 & SOF 7 days + SOF + DCV 23 w & $88 \%(14 / 16)$ & \\
\hline & & & & & 24 w SOF + DCV & $100 \%(14 / 14)$ & \\
\hline & & & & & $24 w S O F+D C V+R B V$ & $93 \%(13 / 14)$ & \\
\hline \multirow[t]{2}{*}{ SOF + GS-581649 } & Gilead & II & 21 & F0-3 only & 12 w SOF + GS-5816 $25 \mathrm{mg}$ & $91 \%(10 / 11)$ & \\
\hline & & & & & 12 w SOF + GS-5816 $100 \mathrm{mg}$ & $100 \%(10 / 10)$ & \\
\hline \multirow[t]{4}{*}{ SOF + GS-58I6 $6^{58}$} & Gilead & II & 103 & F0-3 only & 12 w SOF + GS-5816 $25 \mathrm{mg}$ & $77 \%(20 / 26)$ & \\
\hline & & & & & 12 w SOF + GS-5816 $25 \mathrm{mg}+$ RBV & $88 \%(22 / 25)$ & \\
\hline & & & & & 12 w SOF + GS-5816 $100 \mathrm{mg}$ & $88 \%(23 / 26)$ & \\
\hline & & & & & $12 \mathrm{w}$ SOF + GS-5816 $100 \mathrm{mg}+\mathrm{RBV}$ & $88 \%(23 / 26)$ & \\
\hline \multicolumn{8}{|c|}{ HCV genotype 2 treatment-experienced patients } \\
\hline \multirow[t]{2}{*}{ FUSION ${ }^{40}$} & Gilead & III & 68 & $34 \% \mathrm{~F} 4$ & 12 w SOF + RBV & $86 \%(31 / 36)$ & F0-3: $96 \%(12$ w) vs $100 \%(16$ w) \\
\hline & & & & $25 \%$ prior NR & 16 w SOF + RBV & $94 \%(30 / 32)$ & Cirrhosis: $60 \%(12 \mathrm{w})$ vs $78 \%(16 \mathrm{w})$ \\
\hline \multirow[t]{2}{*}{ VALENCE ${ }^{39}$} & Gilead & III & 41 & $22 \% \mathrm{~F} 4$ & 12 w SOF + RBV & $90 \%(37 / 4 I)$ & F0-3: 94\% (30/32) \\
\hline & & & & & & & F4: 78\% (7/9) \\
\hline
\end{tabular}

Abbreviations: HCV, hepatitis C virus; SVR, sustained virological response; w, weeks; SOF, sofosbuvir; RBV, ribavirin; BMS, Bristol-Myers Squibb; DCV, daclatasvir; $\mathrm{NR}$, null responder; $\mathrm{N}$, number of patients included in the study population; F, METAVIR fibrosis stage.

\section{Sofosbuvir + daclatasvir: SVR I $2=80 \%-89 \%$}

The combination of SOF + DCV has been approved in Europe for the treatment of HCV-2 based on limited Phase II/III data. In a small Phase II study of HCV genotype 2/3 treatmentnaïve patients, including 18 patients with $\mathrm{HCV}-2$, only two of the 18 patients did not achieve SVR12: the first patient was lost to follow-up at treatment week 18, and the second patient failed to attend the week 12 posttreatment visit, but subsequent HCV RNA testing at 24 weeks posttherapy was negative. ${ }^{20}$ This study did not include treatment-experienced patients with $\mathrm{HCV}-2$, but did allow patients with compensated cirrhosis to be enrolled. In a small Phase III study of treatment-experienced $\mathrm{HCV}-1-4$ patients with advanced cirrhosis, the SVR12 rate in patients with HCV-2 that were included in the study was $80 \%(4 / 5) .{ }^{44}$

\section{Interferon-free combinations for HCV genotypes 4-6}

$\mathrm{HCV}$ genotypes (HCV-4-6) represent a smaller proportion of the global burden of HCV infection accounting for only $15 \%$ of $\mathrm{HCV}$ infections worldwide, ${ }^{45}$ and as such there are a limited number of studies investigating IFN-free therapies in the context of these genotypes. Table 6 summarizes the IFN-free combination for HCV-4-6. ${ }^{33,34,43,46-52}$ While caution must be exercised in interpreting these small studies, they provide promising regimens for future therapies.

\section{Promising regimens in Phase II clinical development}

Promising new DAAs, both in combination with approved DAAs and other newer DAAs, as well as combinations of DAAs from different regimens are currently in or have completed Phase II development.

\section{Sofosbuvir + multiple DAA combinations for HCV-I: short-duration therapy}

The main drawback of the new DAAs is their significant cost. This had led to the investigation of combinations of highly potent DAAs from different regimens combined together to determine if therapy could be shortened beyond 12 weeks.

SYNERGY: SOF + LDV \pm GS-9669 or GS-945 I

In this proof-of-concept study, SOF + LDV for 12 weeks was compared to SOF + LDV plus either GS-9669 (a NNI) for 6 weeks or GS-9451 (a NS3/4A PI) for 6 weeks. ${ }^{53}$ This study enrolled treatment-naïve patients with HCV-1, including patients with F3-4 fibrosis (25\%). SVR12 rates were $100 \%$ for the SOF + LDV arm, $95 \%$ for the SOF + LDV + GS-9669 arm, and 100\% for the SOF + LDV + GS-9451 arm. This study provided proof-of-concept that in treatment-naïve patients, therapy can be safely shortened to 6 weeks with combinations of highly potent DAAs. 


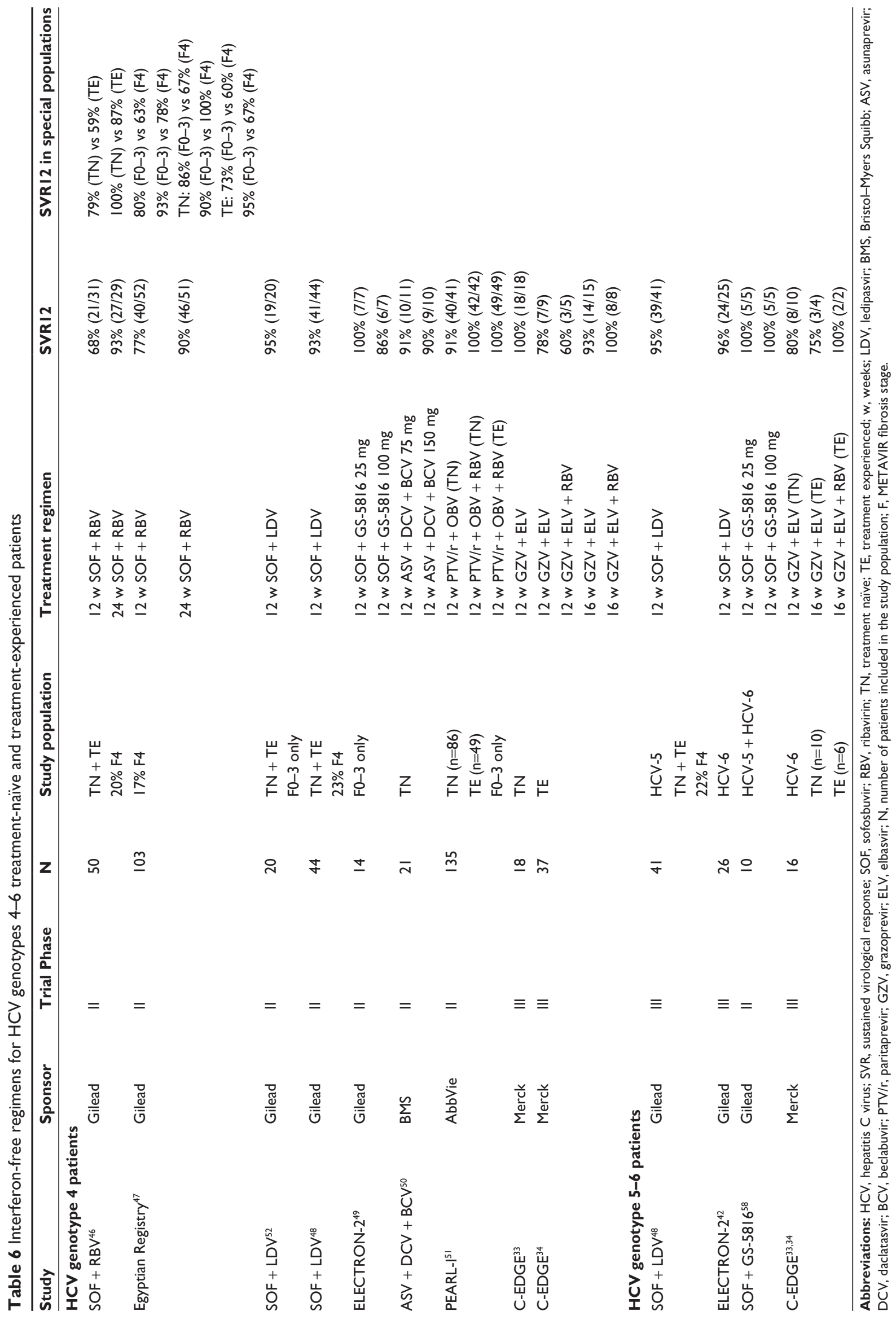




\section{C-SWIFT: GZV + ELV + SOF}

This study also investigated ultra short treatment durations using a multi-DAA combination approach. ${ }^{54}$ Treatment-naïve patients without cirrhosis were randomized to receive GZV + $\mathrm{ELV}+\mathrm{SOF}$ for only 4 weeks or 6 weeks, and treatment-naïve cirrhotics received 6 weeks or 8 weeks of GZV + ELV + SOF. SVR1 2 rates were disappointing for the 4- and 6-week arms $(33 \%$ and $80 \%-87 \%$ for the 4 - and 6-week arms, respectively); however, the 8 -week arm demonstrated high efficacy (94\%), suggesting that 8 weeks of therapy is likely to be sufficient with this combination.

\section{$\mathrm{ACH}-3 \mathrm{IO2}+$ sofosbuvir}

The Phase II PROXY study investigated the next-generation NS5A inhibitor ACH-3102 + SOF in HCV-1 treatment-naïve noncirrhotic patients for either 6 weeks or 8 weeks. SVR12 rates were $100 \%$ in both treatment arms, providing proof that 6 weeks therapy is achievable with highly potent DAA combinations. $^{55}$

\section{Promising pangenotypic regimen: sofosbuvir + GS-5816}

The next-generation NS5A inhibitor GS-5816 has picomolar antiviral activity against all HCV genotypes and has now been examined in small Phase II studies combined with $\mathrm{SOF} \pm \mathrm{RBV}$ in patients with $\mathrm{HCV}-1-6$, with the best results for $\mathrm{HCV}-3$ treatment-experienced patients with cirrhosis to date (Tables 2-6). ${ }^{49,56-58}$ SVR12 rates were between $96 \%$ and $100 \%$ for treatment-naïve and treatment-experienced patients with HCV-1 who received 12 weeks of SOF + GS-5816 $100 \mathrm{mg} \pm \mathrm{RBV}$, including patients with cirrhosis and prior PI failure. ${ }^{49,57,58}$ In patients with HCV-3, SVR12 rates were $96 \%-100 \%$ in treatment-naïve patients, $88 \%-100 \%$ in treatment-experienced patients, and $88 \%-96 \%$ in treatment experienced patients with cirrhosis. ${ }^{57,58}$ SVR12 rates in HCV-2, 4-6 were also very high (91\%-100\%). ${ }^{49}$ In addition, GS-5816 has been shown to have in vitro activity against RAVs selected with the first-generation NS5A inhibitors. As observed with most of the DAA combination regimens, this treatment was very well tolerated, and the most common reported AEs were fatigue, headache, nausea, and diarrhea. This safe pangenotypic 12-week regimen of SOF + GS-5816 with RBV shows significant promise for the difficult to treat populations, including patients with compensated cirrhosis, prior PI failure, and importantly in $\mathrm{HCV}-3$ treatmentexperienced patients with cirrhosis, where current approved IFN-free regimens are suboptimal. This regimen has moved forward into Phase III studies.

\section{Future IFN-free DAA combinations for HCV-3}

Both MK-3682 (NI) and MK-8408 (NS5A inhibitor) show promise in HCV-3. Preclinical and early Phase I/IIa studies have shown the MK-3682 (formerly IDX21437) has a favorable safety profile and picomolar potency against HCV-1-6. ${ }^{59}$ MK-8408 also has a favorable safety profile and has picomolar potency for all HCV genotypes. ${ }^{60}$ These two DAAs are now being testing in combination with GZV (NS3/4A PI) in Phase II clinical trials for HCV-1-4.

\section{Special populations $\mathrm{HCV} /$ human immunodeficiency virus coinfection}

During PR dual therapy, HCV/human immunodeficiency virus (HIV) coinfection represented a more difficult to treat patient population with lower SVR rates compared to HCV monoinfected patients. There are now a growing body of data that show that the efficacy of IFN-free combinations in patients with $\mathrm{HCV} / \mathrm{HIV}$ is identical to $\mathrm{HCV}$ monoinfected patients. ${ }^{61}$ The only consideration in HCV/HIV coinfection is DDIs, particularly with the HCV PIs, which are recognized to have clinically significant DDIs with antiretrovirals, necessitating a change to HIV therapy prior to initiation of HCV PIs.

\section{Decompensated cirrhosis and postliver transplant}

All the Phases I-III programs evaluated IFN-free combinations in patients with compensated cirrhosis. HCV recurrence postliver transplant is universal in viremic patients and is often associated with a more aggressive disease phenotype, with a more rapid onset of fibrosis progressing to cirrhosis, reduced graft survival, and higher patient mortality. Hence, prevention of $\mathrm{HCV}$ recurrence in the graft is a key goal in patients considered for liver transplantation. Early studies have shown that antiviral therapy 30 days prior to transplantation significantly reduces the risk of $\mathrm{HCV}$ recurrence postliver transplantation. ${ }^{62} \mathrm{HCV}$ eradication has also been associated with improved all-cause mortality, and reduced liver-related morbidity, and mortality.,63 "Real-world" data are emerging regarding the use of DAAs in decompensated liver disease. ${ }^{44,64,65}$ The newer PIs are not recommended in patients with decompensated liver disease. Additionally, $\mathrm{SOF}$ is associated with a two-fold increase in its exposure to noncirrhotics compared to patients with cirrhosis, which may have implications on treatment duration. Many of these 
studies have shown a significant improvement in disease severity scores in many patients (eg, Child-Pugh Turcotte or Model for End-stage Liver Disease scores); however, some patients continue to show progressive liver failure, despite successful viral eradication. ${ }^{66}$ Further data are required to determine optimal timing of antiviral therapy in decompensated cirrhotics, where treatment is likely to be of significant benefit. Careful attention to potential DDIs in the setting of immunosuppression posttransplantation must be exercised when administering IFN-free therapies.

\section{$\mathrm{HCV}$ in patients with renal failure}

There is a high prevalence of HCV infection among patients with end-stage renal failure. PR therapy has been difficult in this population for a number of reasons. First, RBV is renally excreted and is not dialyzable. RBV is well known to cause hemolytic anemia, which may be more significant in patients with anemia from their end-stage kidney disease and due to a higher prevalence of comorbidities such as cardiac disease that may complicate management. Furthermore, pegylatedinterferon therapy is contraindicated postrenal transplant due to the high risk of graft rejection.

SOF, one of the main backbones of the current IFN-free combinations, is renally excreted to a large extent and toxic metabolites accumulate in the setting of chronic kidney disease. Hence, this is not recommended in patients with end-stage kidney disease. PTV/r + OBV + DSV and GZV + ELV are not renally cleared, and Phase III studies are currently underway examining the safety and efficacy of these regimens in patients with stage $4 / 5$ chronic kidney disease. Early interim analyses show these regimens are not only highly effective (100\% SVR4 in ten patients treated with the PTV-based regimen, ${ }^{67}$ and SVR12 99\% in the 116 patients who were treated with GZV + ELV ${ }^{68}$ ), but also well tolerated.

\section{Resistance to direct-acting antiviral agents}

There is a high degree of genetic variability in HCV, which results from a high viral replication rate $\left(10^{12}\right.$ virions per day), ${ }^{69}$ and a lack of a proof-reading mechanism by the errorprone RNA-dependent RNA polymerase. ${ }^{70,71}$ The error rate is equivalent to one mutation for every replicated genome. Therefore, it is possible that every genetic variant may be present within the HCV pool, and so HCV is said to exist as a quasispecies. This is an important consideration as mutations may confer resistance to DAAs and be selected during antiviral therapy as demonstrated by the rapid selection of these RAVs during monotherapy with a single DAA. ${ }^{72}$ The majority of RAVs have a replication fitness that is lower than wildtype virus in the absence of drug selection pressure; hence these variants are present in the quasispecies in only a small proportion of patients. The selection of antiviral resistance can be prevented by combination of multiple agents that target different steps in the viral lifecycle. However, treatment failure due to virological breakthrough or relapse in association with the selection of RAVs, is an issue for a minority of patients. Recent data suggests that NS5A variants in particular, frequently present at baseline, are associated with reduced likelihood of SVR in patients with $\mathrm{HCV}-1 \mathrm{a}$ who receive treatment with a regimen including an NS5A inhibitor.

\section{Clinical relevance of baseline (pretreatment) RAVs}

RAVs can develop against any of the targets of DAAs, which may render those DAAs ineffective. Therefore, RAVs already present in pretreatment $\mathrm{HCV}$ quasispecies may impact upon subsequent treatment efficacy, especially if the replication fitness of the RAV is not significantly impaired. The fitness of the RAV, the degree to which the RAV is resistant to the DAA (fold-change in susceptibility), and the HCV genotype and subtype also need to be considered. For example, the main RAV associated with the NI SOF (the S282T RAV) is extremely unfit and has not been detected in the HCV quasispecies of any patients prior to commencing therapy.

\section{Baseline NS3/4A RAVs}

Baseline NS3/4A RAVs significantly impact upon treatment efficacy with some NS3/4A PIs. These RAVs are more common in patients with $\mathrm{HCV}-1$ a due to the low genetic barrier to resistance. In particular, the $\mathrm{Q} 80 \mathrm{~K} / \mathrm{R}$ polymorphism significantly reduces the efficacy of SMV. The frequency of this amino acid substitution, seen exclusively in patients with HCV-1a, varies globally but is as high as $40 \%$ in some regions. Given the significant impact these polymorphisms have on SVR, pretreatment screening is recommended, where the $\mathrm{Q} 80 \mathrm{~K} / \mathrm{R}$ polymorphism prevalence is high, and if present SMV-based regimens may not be recommended. This polymorphism does not exert a whole class effect, and other next-generation PIs are active against this RAV. In the context of regimens, including the next-generation NS3/4A PIs, baseline NS3/4A RAVs do not affect SVR12. ${ }^{33,34,73,74}$

\section{Baseline NS5A RAVs}

The importance of baseline NS5A RAVs is being increasingly recognized. In a pooled post hoc analysis of the Phase III 
SOF + LDV program, the presence of baseline NS5A RAVs in patients with $\mathrm{HCV}-1$ a was associated with significantly lower SVR12 rates, particularly in treatment-experienced patients with baseline NS5A RAVs that conferred a $>100$-fold resistance to LDV, where the SVR 12 rate was only $67 \%$ compared to $9 \%-100 \%$ in patients with $\mathrm{HCV}-1$ a without baseline NS5A RAVs or with NS5A RAVS that conferred a $<100$-fold resistance to $\mathrm{LDV}^{76}$ The presence of baseline NS5A RAVs in patients with $\mathrm{HCV}-1 \mathrm{~b}$ did not affect SVR12. In a similar analysis of the Phase III program for GZV + ELV, baseline NS5A RAVs in patients with HCV-1a negatively impacted upon SVR. ${ }^{33,34}$ In treatment-naïve patients, the SVR12 rate in patients harboring a NS5A variant that conferred $>5$-fold change in ELV susceptibility was only $52 \%$, compared to $99 \%-100 \%$ in those without baseline NS5A RAVs or a NS5A RAV resulting in $<5$-fold reduction in susceptibility to ELV. ${ }^{33}$ In treatment-experienced patients, the impact of baseline NS5A RAVs with a $>5$-fold reduction in susceptibility to ELV was even more pronounced, with an SVR of only $22 \% .{ }^{34}$ These data highlight the differences in RAVs between HCV-1a and HCV-1b, and the significant impact that these NS5A RAVs have on SVR rates in regimens including an NS5A inhibitor. Owing to the very high overall SVR rates with these regimens ( $>90 \%$ ) and the low frequency of these baseline NS5A RAVs (12\%-18\%), testing for these RAVs is not currently recommended in treatment-naïve patients.

\section{Clinical relevance of treatment- emergent variants}

The development of resistance has become a major concern in the era of HCV DAA therapy, and the long-term consequence of these treatment-emergent variants (TEVs) is still to be defined. The most data exist for the first-generation NS3/4A TEVs, which disappear and revert to wild-type following withdrawal of therapy. ${ }^{76,77}$ The majority of patients reverted to wild-type within 3 years, and the median time to undetectable NS3/4A TEVs was 1.11 years. ${ }^{77}$ The newer generation PIs have activity against telaprevir/boceprevir-associated TEVs, and retreatment of these patients with alternative regimens has been successful (Table 3). ${ }^{21,34}$ The impact of NS3/4A TEVs from second-generation PIs remains to be determined; however, these patients have the option to access IFN-free regimens that do not include PIs.

In contrast, data are emerging that the NS5A TEVs can persist 96 weeks posttherapy, ${ }^{74,76,78}$ which has implications for retreatment strategies. This has recently been demonstrated in patients who were retreated with SOF + LDV for 24 weeks after previously failing 8-12 weeks of SOF + LDV. ${ }^{79}$ Of the
41 patients in this cohort, eleven patients did not have detectable NS5A RAVs upon entering the retreatment study. All eleven patients previously received 8 weeks of SOF + LDV, and all eleven patients achieved SVR12 by retreatment with 24 weeks of the same regimen. In the remaining 30 patients with NS5A TEVs following the previous SOF + LDV 8-12week course, the SVR rate was significantly lower: SVR12 was $80 \%$ in patients with NS5A TEV previously receiving 8 weeks and only $46 \%$ in patients with NS5A TEV who received 12 weeks of SOF + LDV, suggesting that the longer the treatment duration, the more likely the development of clinically significant NS5A TEVs. The number of NS5A TEVs present and the type of NS5A TEVs were also associated with SVR, with lower SVR12 rates in patients with $\geq 2$ NS5A TEVs and with the Y93H/N TEV. These emerging data indicate that NS5A TEVs have a drastic impact upon the success of retreatment with regimens, including NS5A inhibitors, thereby significantly limiting retreatment options. Hence, NS5A RAV/TEV testing may be warranted in these patients.

\section{Other predictors of response to IFN-free therapy}

With the very high SVR12 rates of these IFN-free DAA regimens, there are too few patients to be able to perform meaningful subanalyses to inform predictors of treatment response. Unlike with PR therapy, on treatment viral kinetics or time to on-treatment viral suppression does not predict subsequent SVR12 during IFN-free therapies. Baseline NS5A RAVs are increasingly being recognized as an important negative predictor of SVR12, particularly in patients with HCV-1a.

\section{Conclusion}

The rapid development of IFN-free DAA combinations has vastly changed the HCV treatment landscape. The dream of highly effective oral therapy with minimal side effects is now a reality. These IFN-free and often RBV-free regimens have significantly improved SVR 12 rates to $>90 \%$ for most genotypes and most patients, with very short duration of therapy (8-12 weeks) and importantly with significantly improved tolerability, particularly in high-risk populations. This will allow therapy to be available to patients who have previously been ineligible for therapy either due to intolerance or contraindications to prior therapies. However, the cost of these DAAs is significant and will place a large burden on health care expenditure and infrastructure. This has spurred the development of ultra-short regimens (4 weeks of therapy), which are currently 
under clinical evaluation; however, the long-term impact of TEVs has yet to be determined, and this is a key consideration when designing and approving future DAA regimens. Patient adherence will also need to be addressed.

\section{Funding}

JAH received GESA postgraduate scholarship and research/ grant support from Roche and Merck; AJT was the coinventor of a patent related to the IFNL3/IL28B discovery and received research/grant support from Merck, Roche, Gilead Sciences, consulting advisory fees from Merck, Roche, Janssen, Bristol-Myers Squibb, GlaxoSmithKline, Novartis, and Springbank, and speaker fees from Merck, Roche, Gilead Sciences, Bristol-Myers Squibb, and Janssen.

\section{Disclosure}

The authors report no conflicts of interest in this work.

\section{References}

1. Lavanchy D. The global burden of hepatitis C. Liver Int. 2009;29 (Suppl 1):74-81.

2. Davis GL, Alter MJ, El-Serag H, Poynard T, Jennings LW. Aging of hepatitis C virus (HCV)-infected persons in the United States: a multiple cohort model of $\mathrm{HCV}$ prevalence and disease progression. Gastroenterology 2010;138:513-21, 21 e1-e6.

3. Law MG, Dore GJ, Bath N, et al. Modelling hepatitis $\mathrm{C}$ virus incidence, prevalence and long-term sequelae in Australia, 2001. Int J Epidemiol. 2003;32:717-724.

4. van der Meer AJ, Veldt BJ, Feld JJ, et al. Association between sustained virological response and all-cause mortality among patients with chronic hepatitis $\mathrm{C}$ and advanced hepatic fibrosis. JAMA. 2012;308:2584-2593.

5. Manns MP, McHutchison JG, Gordon SC, et al. Peginterferon alfa$2 \mathrm{~b}$ plus ribavirin compared with interferon alfa- $2 \mathrm{~b}$ plus ribavirin for initial treatment of chronic hepatitis C: a randomised trial. Lancet. 2001;358:958-965.

6. Fried MW, Shiffman ML, Reddy KR, et al. Peginterferon alfa-2a plus ribavirin for chronic hepatitis C virus infection. $N$ Engl J Med. 2002;347:975-982.

7. Hadziyannis SJ, Sette H, Jr., Morgan TR, et al. Peginterferon-alpha2a and ribavirin combination therapy in chronic hepatitis $\mathrm{C}$ : a randomized study of treatment duration and ribavirin dose. Ann Intern Med. 2004;140:346-355.

8. Lohmann V, Korner F, Koch J, Herian U, Theilmann L, Bartenschlager R. Replication of subgenomic hepatitis C virus RNAs in a hepatoma cell line. Science. 1999;285:110-113.

9. Bartenschlager R, Lohmann V, Penin F. The molecular and structural basis of advanced antiviral therapy for hepatitis $\mathrm{C}$ virus infection. Nat Rev Microbiol. 2013;11:482-496.

10. Choo QL, Kuo G, Weiner AJ, Overby LR, Bradley DW, Houghton M. Isolation of a cDNA clone derived from a blood-borne non- $\mathrm{A}$, non-B viral hepatitis genome. Science. 1989;244:359-362.

11. Flisiak R, Pawlotsky JM, Crabbe R, et al. Once daily Alisporivir (DEB025) plus pegIFNalfa2A/ribavirin results in superior sustained virological response (SVR24) in chronic heptitits C genotype 1 treatment naive patients. $J$ Hepatol. 2011;54:S2.

12. Buti M, Flisiak R, Kao JH, et al. Alisporivir with peginterferon/ribavirin in patients with chronic hepatitis $\mathrm{C}$ genotype 1 infection who failed to respond to or relapsed after prior interferon-based therapy: FUNDAMENTAL, a Phase II trial. J Viral Hepat 2015;22:596-606.
13. Pawlotsky JM, Flisiak R, Sarin SK, et al. Alisporivir plus ribavirin, interferon-free or in combination with peg-interferon, for HCV genotype 2 or 3 infection. Hepatology. 2015, Jun 27. [Epub ahead of print].

14. Janssen HL, Reesink HW, Lawitz EJ, et al. Treatment of HCV infection by targeting microRNA. N Engl J Med. 2013;368:1685-1694.

15. Afdhal N, Zeuzem S, Kwo P, et al. Ledipasvir and sofosbuvir for untreated HCV genotype 1 infection. N Engl J Med. 2014;370:1889-1898.

16. Kowdley KV, Gordon SC, Reddy KR, et al. Ledipasvir and sofosbuvir for 8 or 12 weeks for chronic HCV without cirrhosis. $N$ Engl J Med. 2014;370:1879-1888.

17. O'Brien TR, Lang Kuhs KA, Pfeiffer RM. Subgroup differences in response to 8 weeks of ledipasvir/sofosbuvir for chronic hepatitis C. Open Forum Infect Dis. 2014;1:1-4.

18. Afdhal N, Reddy KR, Nelson DR, et al. Ledipasvir and sofosbuvir for previously treated $\mathrm{HCV}$ genotype 1 infection. $N$ Engl $J$ Med. 2014;370:1483-1493.

19. Gilead Sciences. Harvoni (ledipasvir and sofosbuvir) product information. In. Foster City, CA; 2014.

20. Sulkowski MS, Gardiner DF, Rodriguez-Torres M, et al. Daclatasvir plus sofosbuvir for previously treated or untreated chronic $\mathrm{HCV}$ infection. N Engl J Med. 2014;370:211-221.

21. Lawitz E, Sulkowski MS, Ghalib R, et al. Simeprevir plus sofosbuvir, with or without ribavirin, to treat chronic infection with hepatitis $\mathrm{C}$ virus genotype 1 in non-responders to pegylated interferon and ribavirin and treatment-naive patients: the COSMOS randomised study. Lancet. 2014;384:1756-1765.

22. Kwo P, Gitlin N, Nahass R, et al. A Phase 3, randomised, open-label study to evaluate the efficacy ad safety of 12 and 8 weeks of Simeprevir (SMV) plus Sofosbuvir (SOF) in treatment-naive and -experienced patients with chronic $\mathrm{HCV}$ genotype 1 infection without cirrhosis: OPTIMIST-1. J Hepatology 2015;62:S270.

23. Lawitz E, Matusow G, De Jesus E, et al. A phase 3, open-label, singlearm study to evaluate the efficacy and safety of 12 weeks of Simeprevir (SMV) plus Sofosbuvir (SOF) in treatment-naive or-experienced patients with chronic HCV genotype 1 infection and cirrhosis: OPTIMIST-2. J Hepatology. 2015;62:S264-S265.

24. Bedossa P, Poynard R. An algorithm for the grading of activity in chronic hepatitis C. The METAVIR Cooperative Study Group. Hepatology. 1996;24(2):289-293.

25. Feld JJ, Kowdley KV, Coakley E, et al. Treatment of HCV with ABT-450/r-ombitasvir and dasabuvir with ribavirin. $N$ Engl $J$ Med. 2014;370:1594-1603.

26. Ferenci P, Bernstein D, Lalezari J, et al. ABT-450/r-ombitasvir and dasabuvir with or without ribavirin for HCV. $N$ Engl J Med. 2014;370:1983-1992.

27. Poordad F, Hezode C, Trinh R, et al. ABT-450/r-ombitasvir and dasabuvir with ribavirin for hepatitis $\mathrm{C}$ with cirrhosis. $N$ Engl $J$ Med. 2014;370:1973-1982.

28. Zeuzem S, Jacobson IM, Baykal T, et al. Retreatment of HCV with ABT-450/r-ombitasvir and dasabuvir with ribavirin. $N$ Engl $J$ Med. 2014;370:1604-1614.

29. Andreone P, Colombo MG, Enejosa JV, et al. ABT-450, ritonavir, ombitasvir, and dasabuvir achieves $97 \%$ and $100 \%$ sustained virologic response with or without ribavirin in treatment-experienced patients with $\mathrm{HCV}$ genotype 1b infection. Gastroenterology. 2014;147:359-365, e1.

30. Lok AS, Gardiner DF, Lawitz E, et al. Preliminary study of two antiviral agents for hepatitis C genotype 1. N Engl J Med. 2012;366:216-224.

31. Kumada H, Suzuki Y, Ikeda K, et al. Daclatasvir plus asunaprevir for chronic HCV genotype 1b infection. Hepatology. 2014;59: 2083-2091.

32. Manns M, Pol S, Jacobson IM, et al. All-oral daclatasvir plus asunaprevir for hepatitis $\mathrm{C}$ virus genotype $1 \mathrm{~b}$ : a multinational, phase 3 , multicohort study. Lancet. 2014;384:1597-1605.

33. Zeuzem S, Ghalib R, Reddy KR, et al. Grazoprevir-Elbasvir Combination Therapy for Treatment-Naive Cirrhotic and Noncirrhotic Patients With Chronic HCV Genotype 1, 4, or 6 Infection: A Randomized Trial. Ann Intern Med. 2015;163:1-13. 
34. Kwo P, Gane E, Peng CY, et al. Efficacy and safety of grazoprevir/ elbasvir +/- RBV for 12 or 16 weeks in patients with HCV G1, G4, or G6 infection who previously failed peginterferon/RBV: C-EDGE treatment-experienced. J Hepatology. 2015;62:S270.

35. Forns X, Gordon S, Zuckerman E, et al. C-SALVAGE: grazoprevir (GZR; MK-5172), elbasvir (EBR; MK-8742) and ribavirin (RBV) for chronic HCV-genotype 1 (GT1) infection after failure of direct-acting antiviral (DAA) therapy. $J$ Hepatology. 2015;62:S190.

36. Poordad F, Sievert W, Mollison L, et al. Fixed-dose combination therapy with daclatasvir, asunaprevir, and beclabuvir for noncirrhotic patients with HCV genotype 1 infection. JAMA. 2015;313:1728-1735.

37. Muir AJ, Poordad F, Lalezari J, et al. Daclatasvir in combination with asunaprevir and beclabuvir for hepatitis $\mathrm{C}$ virus genotype 1 infection with compensated cirrhosis. JAMA. 2015;313:1736-1744.

38. Lawitz E, Mangia A, Wyles D, et al. Sofosbuvir for previously untreated chronic hepatitis C infection. N Engl J Med. 2013;368:1878-1887.

39. Zeuzem S, Dusheiko GM, Salupere R, et al. Sofosbuvir and ribavirin in HCV genotypes 2 and 3. N Engl J Med. 2014;370:1993-2001.

40. Jacobson IM, Gordon SC, Kowdley KV, et al. Sofosbuvir for hepatitis C genotype 2 or 3 in patients without treatment options. N Engl J Med. 2013;368:1867-1877.

41. Nelson DR, Cooper JN, Lalezari JP, et al. All-oral 12-week treatment with daclatasvir plus sofosbuvir in patients with hepatitis $C$ virus genotype 3 infection: ALLY-3 phase III study. Hepatology. 2015;61:1127-1135.

42. Gane EJ, Hyland RH, An D, et al. Sofosbuvir/ledipasvir fixed dose combination is safe and effective in difficult-to-treat populations including genotype- 3 patients, decompensated genotype 1 patients and genotype 1 patients with prior sofosbuvir treatment experience. $J$ Hepatology. 2014;60:S2-S3.

43. Gane EJ, Hyland RH, An D, et al. High efficacy of LDV/SOF regimens for 12 weeks for patients with HCV genotype 3 or 6 infection. Hepatology. 2014;60:1275A-1276A.

44. Poordad F, Schiff ER, Vierling JM, et al. Daclatasvir, sofosbuvir, and ribavirin combination for HCV patients with advanced cirrhosis or post-transplant recurrence: ALLY-1 phase 3 study. J Hepatology. 2015;62:S261-S2.

45. Messina JP, Humphreys I, Flaxman A, et al. Global distribution and prevalence of hepatitis C virus genotypes. Hepatology. 2015;61:77-87.

46. Ruane PJ, Ain D, Stryker R, et al. Sofosbuvir plus ribavirin for the treatment of chronic genotype 4 hepatitis $\mathrm{C}$ virus infection in patients of Egyptian ancestry. J Hepatology. 2015;62:1040-1046.

47. Esmat GE, Shiha G, Omar RF, et al. Sofosbuvir plus Ribavirin in the Treatment of Egyptian Patients with Chronic Genotype 4 HCV Infection. Hepatology. 2014;60:662A.

48. Abergel A, Loustaud-Ratti V, Metivier S, et al. Ledipasvir/sofosbuvir treatment results in high SVR rates in patients with chronic genotype 4 and 5 HCV infection. J Hepatology. 2015;62:S219-S220.

49. Everson GT, Tran TT, Towner WJ, et al. Safety and efficacy of treatment with the interferon-free, ribavirin-free combination of sofosbuvir + GS-5816 for 12 weeks in treatment naïve patients with genotype 1-6 HCV infection. J Hepatology. 2014;60:S46.

50. Hassanein T, Sims KD, Bennett M, et al. A randomized trial of daclatasvir in combination with asunaprevir and beclabuvir in patients with chronic hepatitis $\mathrm{C}$ virus genotype 4 infection. J Hepatol. 2015;62:1204-1206.

51. Hezode C, Asselah T, Reddy KR, et al. Ombitasvir plus paritaprevir plus ritonavir with or without ribavirin in treatment-naive and treatment-experienced patients with genotype 4 chronic hepatitis $\mathrm{C}$ virus infection (PEARL-I): a randomised, open-label trial. Lancet. 2015;385:2502-2509.

52. Kohli A, Kapoor R, Sims Z, et al. Ledipasvir and sofosbuvir for hepatitis C genotype 4: a proof-of-concept, single-centre, open-label phase $2 \mathrm{a}$ cohort study. Lancet Infect Dis. 2015;15:1049-1054.

53. Kohli A, Osinusi A, Sims Z, et al. Virological response after 6 week triple-drug regimens for hepatitis $\mathrm{C}$ : a proof-of-concept phase $2 \mathrm{~A}$ cohort study. Lancet. 2015;385:1107-1113.
54. Poordad F, Lawitz E, Gutierrez JA, et al. C-SWIFT: Grazoprevir/elbasvir + sofosbuvir in cirrhotic and noncirrhotic, treatment-naive patients with hepatitis $C$ virus genotype 1 infection, for durations of 4,6 , or 8 weeks and genotype 3 infection for durations of 8 or 12 weeks. J Hepatology. 2015;62:S192-S3.

55. Gane EJ, Schwabe C, Mader M, et al. Sustained virological response after ACH-3102 and sofoabuvir treatment for 8 or 6 weeks: a phase 2 "Proxy" study. $J$ Hepatology. 2015;62:S266.

56. Gane EJ, Hyland RH, An D, et al. Once daily sofosbuvir with GS-5816 for 8 weeks with or without ribavirin in patients with $\mathrm{HCV}$ genotype 3 without cirrhosis results in high rates of SVR12: the ELECTRON-2 Study. Hepatology. 2014;60:236A-237A.

57. Pianko S, Flamm SL, Shiffman ML, et al. High efficacy of treatment with sofosbuvir + GS-5816 +/- ribavirin for 12 weeks in treatment experienced patients with genotype 1 or $3 \mathrm{HCV}$ infection. Hepatology. 2014;60:297A.

58. Tran TT, Morgan TR, Thuluvath PJ, et al. Safety and efficacy of treatment with sofosbuvir + GS-5816+/- ribavirin for 8 or 12 weeks in treatment naive patients with genotype $1-6 \mathrm{HCV}$ infection. Hepatology. 2014;60:237A.

59. Gupta K, Seifer M, Serra I, et al. Favorable preclinical profile of IDX21437, a novel uridine nucleotide prodrug, for use in a directacting antiviral (DAA) regimen for HCV. J Hepatology. 2014; 60:S504.

60. Asante-Appiah E, Liu R, Curry S, et al. MK-8408, A Potent and Selective NS5A Inhibitor with a High Genetic Barrier to Resistance and Activity Against HCV Genotypes 1-6. Hepatology. 2014;60: $1163 \mathrm{~A}$.

61. Rockstroh JK. Optimal therapy of HIV/HCV co-infected patients with direct acting antivirals. Liver Int. 2015;35 (Suppl 1):51-55.

62. Curry MP, Forns X, Chung RT, et al. Pretransplant sofosobuvir and ribavirin to prevent recurrence of $\mathrm{HCV}$ infection after liver transplantation. Hepatology. 2013;58:314A.

63. D'Ambrosio R, Aghemo A, Rumi MG, et al. A morphometric and immunohistochemical study to assess the benefit of a sustained virological response in hepatitis $\mathrm{C}$ virus patients with cirrhosis. Hepatology. 2012;56:532-543.

64. Reddy KR, Lim JK, Kuo A, et al. All oral HCV therapy is safe and effective in patients with decompensated cirrhosis: report from HCVTARGET. J Hepatology. 2015;62:S193.

65. Foster GR, McLauchlan J, Irving W, et al. Treatment of decompensated HCV cirrhosis in patients with diverse genotypes: 12 weeks sofosbuvir and NS5A inhibitors with/without ribavirin is effective in HCV genotype 1 and 3. J Hepatology. 2015;62:S190-S191.

66. Gambato M, Lens S, Navasa M, Forns X. Treatment options in patients with decompensated cirrhosis, pre- and post-transplantation. J Hepatol. 2014;61:S120-S131.

67. Pockros PJ, Reddy KR, Mantry PS, et al. Safety of ombitasvir/paritraprevir/ritonavir lpus dasabuvir for treatment HCV GT1 infection in patients with severe renal impairment of end-stage renal disease: the RUBY-1. J Hepatology. 2015;60:S257.

68. Roth D, Nelson DR, Bruchfeld A, et al. C-SURFER: grazoprevir plus elbasvir in treatment-naive and treatment-experienced patients with hepatitis $\mathrm{C}$ virus genotype 1 infection and chronic kidney disease. J Hepatology. 2015;60:S263-S264.

69. Neumann AU, Lam NP, Dahari H, et al. Hepatitis C viral dynamics in vivo and the antiviral efficacy of interferon-alpha therapy. Science. 1998;282:103-107.

70. Ogata N, Alter HJ, Miller RH, Purcell RH. Nucleotide sequence and mutation rate of the $\mathrm{H}$ strain of hepatitis $\mathrm{C}$ virus. Proc Natl Acad Sci USA. 1991;88:3392-3396.

71. Steinhauer DA, Domingo E, Holland JJ. Lack of evidence for proofreading mechanisms associated with an RNA virus polymerase. Gene. 1992;122:281-288.

72. Gambarin-Gelwan M, Jacobson IM. Resistance-associated variants in chronic hepatitis $\mathrm{C}$ patients treated with protease inhibitors. Curr Gastroenterol Rep. 2012;14:47-54. 
73. Nguyen LT, Gray E, Dean J, et al. Baseline prevalence and emergence of protease inhibitor resistance mutations following treatment in chronic HCV genotype 1-infected individuals. Antivir Ther. 2015, Apr 29. [Epub ahead of print].

74. Wyles D, Mangia A, Cheng W, et al. Long-term persistence of HCV NS5A variants after treatment with NS5A inhibitor Ledipasvir. J Hepatology. 2015;62:S221.

75. Sarrazin C, Dvory-Sobol H, Svarovskaia ES, et al. The Prevalence and the effect of HCV NS5A resistance associated variants in subjects with compensated cirrhosis treated with ledipasvir/sofosbuvir +/- RBV. J Hepatology 2015;62:S679.

76. Krishnan P, Tripathi R, Schnell G, et al. Long-term follow-up of treatment-emergent resistance-associated variants in NS3, NS5A and NS5B with paritaprevir/r-, ombitasvir- and dasabuvir-based regimens. J Hepatology. 2015;60:S220.
77. Howe AY, Long J, Nickle D, et al. Long-term follow-up of patients receiving boceprevir for treatment of chronic hepatitis C. Antiviral Res. 2015;113:71-78.

78. Dvory-Sobol H, Wyles D, Ouyang W, et al. Long-term persistence of HCV NS5A variants after treatment with NS5A inhibitor ledipasvir. J Hepatology. 2015;62:S221.

79. Lawitz E, Flamm S, Yang JC, et al. Retreatment of patients who failed 8 or 12 weeks of Ledipasvir/Sofosbuvir-based regimens with Ledipasvir/ Sofosbuvir for 24 weeks. J Hepatology. 2015;62:S192.

\section{Publish your work in this journal}

Hepatic Medicine: Evidence and Research is an international, peerreviewed, open access journal covering all aspects of adult and pediatric hepatology in the clinic and laboratory including the following topics: Pathology, pathophysiology of hepatic disease; Investigation and treatment of hepatic disease; Pharmacology of drugs used for the treatment of hepatic disease. Issues of patient safety and quality of care will also be considered. The manuscript management system is completely online and includes a very quick and fair peer-review system, which is all easy to use. Visit http://www.dovepress.com/ testimonials.php to read real quotes from published authors.

Submit your manuscript here: http://www.dovepress.com/hepatic-medicine-evidence-and-research-journal 